\title{
Le soufisme et les soufis selon Ibn Taymiyya
}

Sufism and Sufis according to Ibn Taymiyya

$$
\text { التصّوف والمتصوّفون عند ابن تيميّة }
$$

\section{Qais Assef}

\section{OpenEdition}

\section{Journals}

Édition électronique

URL : http://journals.openedition.org/beo/330

DOI : $10.4000 /$ beo.330

ISBN : 978-2-35159-335-6

ISSN : 2077-4079

\section{Éditeur}

Presses de l'Institut français du Proche-Orient

\section{Édition imprimée}

Date de publication : 1 mai 2012

Pagination : 91-121

ISBN : 978-2-35159-193-2

ISSN : 0253-1623

\section{Référence électronique}

Qais Assef, "Le soufisme et les soufis selon Ibn Taymiyya », Bulletin d'études orientales [En ligne], Tome LX I mai 2012, mis en ligne le 31 mai 2012, consulté le 10 décembre 2020. URL : http:// journals.openedition.org/beo/330; DOI : https://doi.org/10.4000/beo.330 


\title{
LE SOUFISME ET LES SOUFIS SELON IBN TAYMIYYA ${ }^{1}$
}

\author{
Qais ASSEF
}

Institut français du Proche-Orient/École pratique des hautes études

Héritée del'orientalisme duxix ${ }^{\mathrm{e}}$ siècle (MAKDISI 1983, p. 43-49), et accentuée parl'avènement du wahhabisme et du salafisme, la réputation anti-soufie d'Ibn Taymiyya n'a cessé de voiler la réalité de son œuvre à portée mystique ${ }^{2}$. Ce n'est que tardivement que l'on a vu l'audace de certains chercheurs percer, ici et là, l'épais brouillard couvrant l'immense héritage du šayh alislām. Force est de constater que l'entreprise n'en est qu'à ses balbutiements. Cependant, ces travaux pionniers ont permis de révéler les affinités d'Ibn Taymiyya et de son école hanbalite avec la mystique musulmane ${ }^{3}$. Une chose est certaine, il n'existe aucun écrit du savant hanbalite condamnant le soufisme en tant que tel ${ }^{4}$. Faire du šayh al-islām un opposant à la mystique, reviendrait à négliger son acuité d'analyse et sa modération en termes de jugement. Selon Ibn Taymiyya, il ne faut rien rejeter en bloc, et « la seule chose qu'il soit correct de faire, c'est [cependant] de juger véridique le vrai et de traiter le mensonge de vain ${ }^{5}$ ». L'idée d'une antinomie entre un sunnisme "orthodoxe", incarné par le savant hanbalite, et la mystique résulte en réalité d'une lecture partielle et hors contexte de son œuvre. En effet, les écrits d'Ibn Taymiyya, saisis dans leur contexte historique, témoignent non seulement d'une doctrine favorable à la mystique, mais s'en trouvent fortement influencés. Ce qui n'est pas sans surprendre Chodkiewicz (1984a, p. 192-193) qui, à propos de la position du docteur

1. Je tiens à remercier Madame Denise Aigle, Messieurs Éric Geoffroy et Pierre Lory pour leurs précieux conseils. J'exprime également ma reconnaissance à mes professeurs d'arabe, messieurs Walid al-Hafez et Jamal Chehayed, pour leur inestimable apport. Enfin, je salue le travail de relecture de Robin Beaumont, Jean-Charles Coulon, JeanYves L'Hopital et de mon épouse Georgette Musong Assef.

2. Pour la « wahhabisation » progressive de l'islam sunnite et l'hostilité de Muhammad b. 'Abd al-Wahhāb (17031792) envers le soufisme, voir PESKEs 1999.

3. MAKDISI, 1973, 1974, 1984 ; Michel1981 ; Homerin 1985 ; GeOFFroy 1995 b.

4. Pour un aperçu des doctrines soufies incriminées par Ibn Taymiyya, voir Laoust 1962, p. 32-34. Sur l'influence posthume d' Ibn Taymiyya, voir Laoust 1939, p. 475-575, et Laoust 1962, p. 44-47.

5. Iвn TауміучA, Mağmū al-fatāwā, vol. XI, p. 434 ; cité par Мıснот 2007, p. 56. Plus aveugle sera cependant la condamnation du soufisme par les épigones wahhabites d'Ibn Taymiyya, dont le fondateur Muhammad b. 'Abd al-Wahhāb n'opérait pas de distinction entre les pratiques populaires et celles du soufisme. Voir PESKES 1999, p. 153 et 159. 
hanbalite sur l'extinction mystique (fana'), affirmait: « un tel langage paraît surprenant et presque incongru sous la plume d'un auteur peu porté aux professions de foi soufies ».

\section{PRÉCISIONS MÉTHODOLOGIQUES}

Létude de la perspective taymiyyenne du soufisme nécessite des précautions d'ordre méthodologique. Rappelons que « soufisme » est un terme synthétique qui, dans sa réalité vécue, comprend une riche palette de types spirituels donnant lieu à diverses doctrines et pratiques ${ }^{6}$. En outre, celles-ci ont évolué au fil du temps, mais peuvent tout aussi bien se distinguer d'une région à l'autre à une même époque (CНАBвI 1977, p. 5-8).

D'autre part, l'idée, encore persistante, d'une opposition intrinsèque entre « orthodoxie » sunnite et mystique contribue à une approche incertaine du soufisme. En effet, «l'orthodoxie », pas plus que le soufisme, ne désigne une doctrine fixe dans le temps et dans l'espace. McGregor (2009, p. 69-74) emprunté à la chrétienté, est inadapté pour rendre pleinement le caractère pluraliste et complexe de la vie religieuse dans les sociétés musulmanes. Les appréciations paradoxales émises par les docteurs de la Loi à propos des soufis illustrent parfaitement cette « orthodoxie " à géométrie variable. À titre d'exemple, Ibn Taymiyya a commenté plusieurs écrits mystiques, dont ceux du soufi hanbalite 'Abd al-Qādir al-Ğîlānī (m. 1166) ${ }^{7}$; l'un des maîtres de ce dernier, Ḥammād al-Dabbās (m. 1130), bénéficiait d'une grande estime auprès du šayh al-islām ${ }^{8}$. Cette attitude contraste avec celle du hanbalite Ibn 'Aqīl (m. 1119) qui, deux siècles plus tôt à Bagdad, avait sévèrement critiqué Dabbās, lui reprochant de pratiquer un soufisme suspect ${ }^{9}$.

Bien qu'en voie d'abandon, « l'abstraction outrancière et les procédés généralisateurs et comparatistes abusifs » (С à des études plus approfondies sur le rapport entre hanbalisme et soufisme et plus particulièrement sur l'œuvre mystique d'Ibn Taymiyya.

Ses écrits, souvent de circonstance (CHodkiewicz 1984b, p. 99), nécessitent que l'on en précise le contexte, et donc la portée. D'une manière générale, l'œuvre d'Ibn Taymiyya ne peut être comprise sans une connaissance du contexte politique, social et religieux dans lequel il évoluait. Son « action est si étroitement liée à l'histoire des premiers Mamlouks qu'on ne peut pleinement comprendre l'une sans l'autre »(LAoust 1960, p. 2).

D'ailleurs, Ibn Taymiyya est-il l'ennemi du soufisme, des soufismes ou bien d'une certaine forme de soufisme? Nous constatons que le pluriel n'a été que rarement employé dans ce genre de questionnement. Henri Laoust (1939, p. 89-93) fut parmi les premiers à souligner les affinités du šayh al-islām avec le soufisme, nuançant de ce fait la réputation

6. Pour une typologie spirituelle du tașawwuf, voir Geofrroy 1995a, p. 283-360.

7. La vénération d'Ibn Taymiyya pour ce maître soufi est si grande qu'il le qualifie de " pôle des connaissants » (quțb al-'ārifīn), voir IBN TAYmiYYA, Al-Istiqāma, vol. I, p. 85. Pour le commentaire des Futūḥ al-ġayb de Ǧīlānī, voir IBN TAYMiYya, Mağmū' al-fatāwā, vol. X, p. 455-548. Voir également Michel 1981.

8. Ibn Taymiyya classe Ḥammād al-Dabbās et 'Abd al-Qādir al-Ǧīlānī parmi les « mašảihh ahl al-istiqāma », (voir IBN TAYмiYYA, Mağmū' al-fatāwā, vol. X, p. 516).

9. MAKDISI 1963, p. 376, n.1 et p. 383, n. 1 . 
anti-soufie dans laquelle était cloisonné le savant hanbalite. Des études postérieures sont venues confirmer ces affinités (MAKDIsI 1983, p. 54), allant même jusqu'à suggérer son appartenance à la confrérie soufie Qādiriyya (MAKDISI 1973). La relative abondance "d'arguments » en faveur d'une adhésion d'Ibn Taymiyya au « soufisme » ne saurait être décisive, sans un examen attentif des interactions entre le supposé adepte et les multiples dimensions de la mystique musulmane. En effet, l'emploi du terme «soufisme» limite notre compréhension de la mystique à certains de ses aspects.

D'une manière générale, la mystique pose un problème d'approche méthodologique, car il ne s'agit pas seulement de s'en tenir à une analyse phénoménologique de l'expérience religieuse. «L'objet étudié est alors un mystère personnel, de soi ineffable au surplus, celui des rapports les plus profonds qui puissent être sur terre entre l'âme et Dieu » (GARDET et AnaWaTi 1976, p. 14). Anawati et Gardet (1976, p. 15) insistent sur la nécessité de « distinguer entre l'expérience mystique elle-même et son expression conceptuelle ou verbale ». En effet, le chercheur, ne disposant que d'écrits, peut se trouver devant une expérience mystique profonde mal conceptualisée ou bien inversement, devant une doctrine mystique harmonieuse sans aucune réalité vécue. Anawati et Gardet (1976, p. 15) ajoutent que «l'expérience mystique étant quelque chose d'essentiellement personnel, ne peut être interprétée qu'à la lumière de la vie même du mystique, au-delà de son expression verbale ».

Cette précaution d'ordre méthodologique est rappelée par Garcin (2006, p. 11) qui met en garde l'historien "généraliste » contre les erreurs d'appréciation dans l'approche du soufisme. Quant à l'interrogation de l'historien concernant la « légitimité d'une enquête simplement historienne » sur le soufisme, - «surtout si elle est le fait d'un historien qui n'est pas lui-même musulman » (GARCIN 2006, p. 12-14) - le spécialiste du soufisme, Gril (2006, p. 72), répond qu'il n'est pas nécessaire d'être «soufi, ni même musulman, pour pénétrer cet univers. [...], il suffit d'en connaître les codes».

Bien que formulée, la question de l'adhésion d'Ibn Taymiyya au soufisme reste somme toute secondaire aux yeux de l'islamologue. D'ailleurs, toute affirmation sur le sujet nécessiterait que l'on établisse les critères objectifs permettant d'identifier un adepte du " soufisme ", dans le Damas mamelouk des xiII et xIV siècles ${ }^{10}$. La tâche est d'autant plus difficile que le tașawwuf revêt de multiples formes, notamment à cette époque ${ }^{11}$. Plutôt que l'adhésion en elle-même, le chercheur sur la mystique s'intéressera à l'origine et au degré de cette affiliation ${ }^{12}$. Est-elle uniquement d'ordre social (" confrérique ») ${ }^{13}$ ? S'agit-il d'une

10. Question également posée par D. Gril pour un contemporain d'Ibn Taymiyya vivant en Haute-Égypte. Voir GRIL 2006, p. 56.

11. Pouzet 1991, p. 207-243. D’autre part, les questions posées au début de L'épitre des soufis, font part de la multiplicité des voies soufies (suluk), sur lesquelles Ibn Taymiyya doit se prononcer.

12. Outre les maîtres « authentiques » du soufisme (mašă’h ahl al-istiqāma) qu'Ibn Taymiyya cite explicitement, il serait intéressant de retracer la «filière mystique » dont ses écrits se font l'écho. Le gigantisme de son œuvre, la complexité du contexte historique et la persistance des préjugés à son propos, risquent cependant de rendre l'enquête longue et fastidieuse.

13. Sur les voies soufies, voir GriL $1996 \mathrm{~b}$ et GEOFFroy 1996. 
pratique régulière de certains rites, de simples affinités avec les doctrines et l'éthique du soufisme ${ }^{14}$, ou bien d'une adhésion totale, vécue dans sa forme extérieure comme dans ses réalités métaphysiques (haqā’iq)?

Ces remarques et interrogations suggèrent une redécouverte de l'œuvre d'Ibn Taymiyya et de son milieu selon une approche micro-historique ${ }^{15}$, accompagnée d'une démarche attentive aux multiples dimensions et expressions de la mystique musulmane. En effet, il ne s'agit plus d'étudier les autorités religieuses sous l'angle exclusivement islamologique, mais de privilégier « une approche attentive aux individus et à leurs paroles, saisis dans leurs relations à d'autres individus, [...]. L'historien se doit de suivre le destin d'un homme ou d'un groupe d'hommes - et avec lui la multiplicité des espaces et des temps, l'écheveau des relations dans lesquelles il s'inscrit » (Aigle 2010, p. 16).

\section{L'ÉPÎTRE DES SOUFIS ET LE CONTEXTE HISTORIQUE}

À défaut de pouvoir nous prononcer, dans l'immédiat, sur une éventuelle « affiliation » du šayh al-islām au "soufisme ", nous proposons d'examiner son opinion vis-à-vis du tașawwuf et de ses adeptes, opinion qu'il expose dans l'épître al-Ṣüfiyya wa-l-fuqarā' ${ }^{16}$, dont nous proposons ci-après une traduction. L'épittre des soufis débute par un court exposé sur l'origine du soufisme, à la suite de quoi Ibn Taymiyya aborde le sujet principal de son épître, les états spirituels ( $a h w w \bar{a} l$ sing. h hāl). Après avoir passé les états spirituels des soufis au crible du Coran, de la Sunna et du consensus des Salaf, le savant hanbalite répond aux questions initiales sur les différentes catégories de soufis. Relativisant l'importance des désignations et des catégories qu'il a énumérées précédemment, Ibn Taymiyya conclut en invoquant la hiérarchie des croyants et leurs qualités intrinsèques selon la Révélation.

Le style simple et didactique de L'épitre des soufis nous indique qu'elle est destinée à un large public. Les questions, formulées au début de l'épître, semblent confirmer cette hypothèse. En effet, il s'agit de discerner, parmi les différentes sortes de soufis, les caractéristiques de chaque fraction et d'en déterminer la légalité. Toutefois, le caractère "généraliste » de l'épître n'empêche pas Ibn Taymiyya de faire référence, fût-ce furtivement, aux débats doctrinaux autour du soufisme, notamment sur les conditions de la « sainteté » (walāya), qu'il évoque en fin d'exposé. Quant au lecteur « spécialiste », il est avisé que «cette réponse contient des propos nécessitant de longues explications, qui ne peuvent se faire ici ${ }^{17} »$.

Bien que le cadre historique semble être celui des premiers renonçants (zuhhād sing. $z a \overline{h i d}$ ) de Bassora, une lecture attentive confrontée aux données historiques nous permet d'entrevoir un texte d'une brûlante actualité ${ }^{18}$. Ce que Homerin, dans sa traduction

\footnotetext{
14. À propos des doctrines et pratiques soufies, voir GrIL 1996a.

15. Sur la micro-histoire, voir Aigle 2010, p. 14-18.

16. Texte arabe dans IBn TAYmiYyA, Mağmū' al-fatāwā, vol. XI, p. 5-24, désormais : L'épître des soufis.

17. Avis partagé par Homerin 1985, p. 220.

18. Le texte étant très allusif, nous ne pouvons le dater avec précision.
} 
(1985, p. 220), signalait comme de simples digressions, sont en réalité des références implicites à ses contemporains.

Le passage concernant les moyens illicites d'aboutir à l'ivresse spirituelle vise très probablement ses contemporains ${ }^{19}$. Il y dénonce la consommation de vin, de haschich mais également l'amour et la passion des formes, ainsi que le samā. Nous savons par ailleurs le penchant des Haydariyya ${ }^{20}$ de Damas pour le haschich ${ }^{21}$. De même, il est attesté que la pratique du samā', à son époque, était dans certains cas accompagnée de danse et de vin ${ }^{22}$. Quant à l'amour et la passion des formes, il semble qu'Ibn Taymiyya se réfère à ceux de ses contemporains qui s'adonnaient à la contemplation de jeunes garçons imberbes ${ }^{23}$.

Ailleurs, le savant hanbalite fait allusion à « la fameuse divergence à propos de celui qui prononce la répudiation (țalāq) en état d'ébriété ${ }^{24} »$. Il semble que dans ce passage il apporte furtivement un argument pour soutenir sa position, qui consiste à refuser le regroupement des trois formulations de divorce en une seule. Pour rappel, cette position lui valut, en 1318, l'interdiction du sultan d'émettre des fatwā-s sur le sujet et, en septembre 1320, il fut condamné à l'emprisonnement pour avoir enfreint l'interdiction sultanienne.

C'est encore à ses contemporains qu'lbn Taymiyya adresse ses griefs lorsqu'il fait allusion aux dérives du soufisme « étatique » (șūfiyyat al-arzāq), institutionnalisé et financé par les grands de ce monde. À ce sujet, L. Pouzet mentionne la confrérie Qalandariyya qui reçut, de Kitbuğā, dix mille pièces d'argent en $1296^{25}$.

Bien que ces allusions restent périphériques, l'épître illustre parfaitement l'étroite corrélation entre l'œuvre et l'environnement immédiat du savant hanbalite.

\section{TYPES SPIRITUELS ET DEGRÉS DE RÉALISATION}

À l'instar du Kitāb al-ta'arruf de Kalābād̄ī (m. 998) ${ }^{26}$, L'épittre des soufis débute par l'analyse lexicale du terme «s súfì I Ibn Taymiyya analyse, à travers le prisme de la linguistique et de la logique, quelques-unes des «filiations » proposées par les manuels de soufisme. Il en déduit que l'adjectif de relation «s sŭfì» ne peut faire référence qu'à l'habit de laine (șŭf $)^{27}$. La suite de l'épître nous induit à penser que cette précision est loin d'être anodine. En effet, les autres origines possibles du terme "șūfì», que le savant hanbalite a éliminées, sont des termes

19. Iвn TAYмiYya, Mağmū' al-fatāwā, vol. XI, p. 10-11.

20. À propos des Haydariyya et de la consommation de haschich, voir Мichoт 2001a, p. 40, n. 3 ; GeofrRoY, p. 69-70. Sur leur implantation à Damas, voir PouzET, 1991, p. 228-229.

21. Sur la consommation du haschich dans les milieux mystiques, voir Мiснот 2001a, p. 38-51 et GeOfFroy 2010, p. $70-72$.

22. Ibn Taymiyya raconte une telle scène dont il dit avoir été témoin (voir IBN TAYMIYYA, Mağmū'al-fatāwāa, vol. X, p. 418-419 ; trad. Міснот 1991, p. 23-24).

23. Pouzet 1983, p. 132 ; Homerin 1985, p. 226, n. 32.

24. Iвn TAYмiyya, Mağmū' al-fatāwā, vol. XI, p. 11.

25. Voir infra, n. 169. Sur l'intérêt des émirs mamelouks pour certains « ordres » soufis, voir GARCIN 2006, p. 32.

26. KALĀBĀD̄Ī, Traité de soufisme, p. 25-31.

27. IBn TAYMiYya, Mağmū' al-fatāwā, vol. XI, p. 6 ; KaLĀBĀD̄Ī, Traité de soufisme, p. 30. 
élogieux ${ }^{28}$ tels « ahl al-ṣuffa ${ }^{29}$ » (les Gens du banc), « le rang (șaff) avancé se tenant devant Dieu » et « l'élite (safwa) de la création de Dieu ». Ibn Taymiyya tente, tout au long de son exposé, de distinguer les soufis authentiques des pseudo soufis ${ }^{30}$, qui se complaisent dans le fait d'en porter le titre ${ }^{31}$. C'est dans ce même esprit qu'Ibn Taymiyya évoque l'apparition tardive du terme "șūfì», qui selon lui daterait de l'époque de Hasan al-Bașrī (m. 728).

Conscient des « réalités métaphysiques » (haqā’iq) sous-jacentes au terme « tașawwuf », Ibn Taymiyya relativise ses manifestations extérieures et aborde l'essence même du cheminement soufi : les états spirituels, que Kalābād̄i nomme par ailleurs « les sciences des soufis ${ }^{32}$ ».

L'apparition tardive du terme et du " phénomène » soufi à Bassora ne fait pas pour autant du tașawwuf une innovation (bid'a) aux yeux d'Ibn Taymiyya. Bien au contraire, les états spirituels du soufi et la science qui en découle remontent, selon lui, au Prophète et à ses compagnons. En outre, « les états spirituels (aḥwäl) atteints par les Compagnons sont ceux mentionnés dans le Coran ${ }^{33} »$.

Pour les ahl al-sunna wa-l-ğamāa $a$, de qui le savant hanbalite se réclame, le Coran, la Sunna et le consensus de la communauté musulmane (iğma'), forment les trois fondements de la religion ${ }^{34}$. Et c'est selon ces trois principes que l'on doit juger « les paroles et les actes des hommes dans leur réalité intérieure (bāțin) et leurs manifestations extérieures (zāhir) ${ }^{35} »$. Sans rejeter le consensus de ses contemporains, qui reste selon lui discutable, Ibn Taymiyya affirme que «le seul consensus qui soit bien établi est celui des vertueux Ancêtres (al-salaf al-șālih car, après eux, les divergences se sont accrues et la communauté (umma) s'est divisée ${ }^{36} »$.

De là procèdent ses nombreuses références aux trois premières générations (al-qurūn al-țalāta ${ }^{37}$, qui représentent, à ses yeux, «l'âge d'or » de l'islam (al-qurūn al-talāta al-mufaḍ̂lala). C'est même « un principe fondamental dans le concept historique d'Ibn Taymiyya (OLESEN 1991, p. 55)». La meilleure des époques est, selon un hadith, celle à laquelle le Prophète fut envoyé ${ }^{38}$. De ce fait, plus on s'éloigne de l'époque de la Révélation, plus la religion est en proie aux innovations et, par conséquent, aux

28. À l'exception du nom de la tribu antéislamique (Șufa b. Bišr b. Addi b. Țābiha) qu'Ibn Taymiyya écarte pour des motifs historiques.

29. Voir WaTT 1960.

30. Sur les pseudo-soufis, voir GEOFFroy 1995a, p. 175-187.

31. Le problème de la forme et des réalités métaphysiques du soufisme était déjà soulevé au $\mathrm{x}^{\mathrm{e}}$ siècle par Huğwirī (m. 1072) : " c'est aujourd'hui un nom sans réalité alors que c'était jadis une réalité sans nom », cité par CHODKIEWICZ 1984c, p. 42.

32. Cité par KALĀBĀDIĪ, Traitéde soufisme, p. 91 : « Sache que les sciences des soufis sont les sciences des états spirituels. »

33. Iвn TAYMiYYA, Mağmū' al-fatāwā, vol. XI, p. 8.

34. Sur la méthodologie d'Ibn Taymiyya et les fondements de la religion, voir LAOUST 1939, p. 226-259 ; IBN TAYMIYYA, La profession de foi d'Ibn Tamiyya, p. 84, n. 260.

35. Iвn Taymiyya, La profession de foi d'Ibn Tamiyya, p. 84.

36. IBn TAYMiyya, La profession de foi d'Ibn Tamiyya, p. 84.

37. Pour la définition d'al-qurūn al-țalāta, voir IBN TAYMIYYA, Mağmū' al-fatāwā, vol. XXVII, p. 384-385.

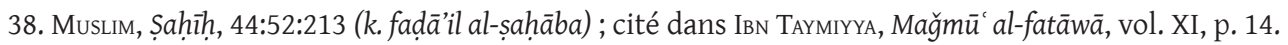


divisions ${ }^{39}$. Le soufisme n'échappe guère à cet effet de corrosion, dû à l'éloignement dans le temps de l'époque prophétique. Et ce n'est qu'en luttant activement contre les innovations, contraires aux fondements de la religion, que l'on peut en limiter l'effet dissolvant sur l'héritage du Prophète ${ }^{40}$.

La référence aux trois premières générations (al-qurūn al-țalāta) permet à Ibn Taymiyya, non pas de condamner, mais bien au contraire, d'excuser certains excès des générations postérieures, privées de la «lumière » immédiate du Prophète, des Compagnons ou des Suivants. Ainsi, Ibn Taymiyya ne désapprouve pas ceux qui, à Bassora, s'adonnaient à « une certaine exagération, dans le renoncement (zuhd), la dévotion ('ibāda), la crainte de Dieu (hawf), etc. ${ }^{41}$ ». Loin de l'image de rigoriste qu'on lui prête, la position du šayh al-islām est faite de nuances, et même d'indulgence envers l'ivresse spirituelle et les extatiques. Il va même jusqu'à excuser les paroles insensées proférées par ces derniers alors qu'ils sont en état d'ivresse spirituelle ${ }^{42}$. Par ailleurs, il fait preuve de la même mansuétude envers les «locutions théopathiques » (šatahāt) de Bisțāmī (m. 877) ${ }^{43}$, de Nūrī (m. 907) ou de Šiblī (m. 945) :

«Ainsi, il se produisit chez [certains] maîtres soufis, une extinction mystique (fanā) et une ivresse spirituelle (sukr) entraînant l'altération de leur discernement au point que certains ont tenu, en cet état, des propos qu'ils considérèrent comme erronés, une fois revenus à eux-mêmes. De tels faits sont rapportés à propos d'Abū Yazīd [al-Bisțāmī] par exemple, d'Abū al-Ḥasan al-Nūrī, d'Abū Bakr al-Šiblī et de leurs semblables ${ }^{44}$.»

Fidèle à sa méthodologie ${ }^{45}$, l'indulgence d'Ibn Taymiyya ne concerne cependant que les causes licites de l'ivresse spirituelle, c'est-à-dire le samä du Coran ${ }^{46}$, la mention des noms de Dieu (dikr), ou toute cause involontaire, telle l'audition fortuite (samä' lam yaqșidhu) ${ }^{47}$. C'est ainsi qu'il condamne, avec une grande fermeté, l'état d'ivresse spirituelle obtenue par des moyens jugés illicites: « la consommation d'enivrants, telles les boissons alcoolisées et le haschich ${ }^{48}[. .$.$] , l'amour et la passion des formes, [...] l'audition \left(s a m \bar{a}^{c}\right)^{49}$ des "voix ravissantes" (al-așwāt al-mutriba) ${ }^{50}$ ".

\footnotetext{
39. Sur le thème de la dégénérescence du temps, voir Geofrroy 1995a, p. 176-177.

40. Concernant sa position vis-à-vis des innovations, voir IBN TAYMIYYA, La profession de foi d'Ibn Tamiyya, p. 83, n. 256.

41. Iвn TAYмiYYa, Mağmū' al-fatāwā, vol. XI, p. 6.

42. IвN TAYмiYYA, Mağmū' al-fatāwā, vol. XI, p. 10.

43. À propos d'Abū Yazīd Bisțāmī et de ses šath, voir MAssignon 1999, p. 273-287. C'est également à Massignon que nous empruntons l'expression « locutions théopathiques ».

44. Iвn TAYmiYya, Mağmū' al-fatāwā, vol. X, p. 220-221.

45. C'est-à-dire aux trois fondements de la religion : le Coran, la Sunna et le consensus des Salaf.

46. Concernant sa position sur le samāc, voir Мıснот 1991.

47. Concernant l'audition fortuite, voir Мiснот 1991, p. 65-67.

48. Sur le haschich, voir le recueil des fatwa d'Ibn Taymiyya traduit par Мiснот 2001a, p. 77-153.

49. Kalābād̄ī vante les bienfaits du samāc, de même que Ǧunayd y est favorable (voir KaLĀBĀD̄ī, Traité de soufisme, p. 183-184).

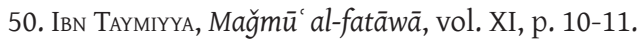


Toutefois, Ibn Taymiyya signale que le Prophète et les Compagnons ne perdirent point le discernement lors des inspirations subites (wārid) et que leur état est en tout point préférable. Il se réfère ainsi à l'expérience de l'ascension céleste (mi'rāğ) du Prophète, dont l'état resta inchangé, comme s'il n'avait jamais quitté sa demeure ${ }^{51}$. Et dans la lignée du Prophète et des Compagnons, le savant hanbalite inclut certains maîtres du soufisme, qui surent rester stables :

«De par l'entendement et le discernement qui les accompagnaient lors de leurs états spirituels, ne sont tombés, dans de telles extinctions mystiques, ivresses spirituelles, etc., ni Abū Sulaymān al-Dārānī, ni Ma rūf al-Karhīin ni Fuḍayl b. 'Iyād [et encore moins] Ğunayd et ses semblables ${ }^{52}$."

Mais l'extatique, perdant tout discernement, est d'autant plus excusable qu'un tel état est mentionné dans le Coran à propos du prophète Moïse, qui «tomba foudroyé lorsque Dieu se présenta au Mont ${ }^{53}$ ». Considérant l'état spirituel de Moïse comme vénérable, élevé et méritoire, Ibn Taymiyya note cependant que l'état spirituel de Muhammad, de par sa stabilité, est plus complet, plus élevé et préférable.

Cette opinion se retrouve également chez Kalābādīi qui affirme que « celui dont l'extase est forte reste maître de soi et calme ${ }^{54} »$. S'appuyant sur les propos de Ğunayd, l'auteur du Ta'arruf précise que l'extase n'est pas un but en soi ; l'extase est transitoire alors que «la connaissance (márifa), elle, est stable et ne passe pas ${ }^{55}$ ». De même, Kalābādī considère que l'état d'emprise (ǵalaba) conduisant à la perte de discernement reste admissible, même si un état stable lui est préférable ${ }^{56}$.

Selon Ibn Taymiyya, l'application personnelle (iğtiḥād) des soufis et les divergences qui en découlent (tanāzu' fì-hi) ont conduit certains imams à jeter l'anathème sur le soufisme en tant que tel. Cependant, le šayh al-islām rejette explicitement une telle condamnation du soufisme, de même qu'il désavoue toute exagération dans l'éloge des soufis ${ }^{57}$. Dans un autre passage des Mağmū' al-fatāwā, il affirme à propos de la voie soufie :

«[Pourtant] ce qui est correct, c'est seulement d'entériner ce qui, en cette [voie] et en d'autres, est en accord avec le Livre et la Sunna, et de dénoncer ce qui, en elle et en d'autres, est en opposition avec le Livre et la Sunna ${ }^{58}$.»

Se référant aux fondements de l'islam, son réformisme religieux s'applique ainsi à épurer la mystique musulmane des innovations (bid'a) et des imposteurs ${ }^{59}$, «à l'exemple

51. Notons qu'ici, Ibn Taymiyya analyse le mírāğ du Prophète dans la perspective d'une expérience mystique.

52. Iвn TAYmiYya, Mağmū' al-fatāwā, vol. X, p. 221.

53. Coran $7: 143$; cité dans IBN TAYmiYya, Mağmū' al-fatāwā, vol. XI, p. 13.

54. KALĀBĀ̄DII, Traité de soufisme, p. 124.

55. KALĀBĀD̄I, Traité de soufisme, p. 124.

56. KALĀBĀ̄̄I, Traité de soufisme, p. 128.

57. Iвn TAYмiYya, Mağmū' al-fatāwā, vol. XI, p. 18.

58. Iвn Tауміуча, Mağmū' al-fatāwā, vol. X, p. 82 (trad. Мıснот 2000, p. 1).

59. Idée du muğaddid exprimée dans IBN TAYмIYYA, Mağmū' al-fatāwā, vol. XI, p. 434-435. 
de Ḥallāğ, que les maîtres [du soufisme], tel Ğunayd, le "Prince de l'Ordre", ont désavoué et exclu de la voie ${ }^{60}$.»

\section{SOUFIS ET HIÉRARCHIE SPIRITUELLE}

Après l'exposé sur les conditions de licéité de l'extase, le šayh al-islām positionne le soufi dans la hiérarchie spirituelle, telle qu'elle est définie par le Coran : "Ceux que Dieu a comblés de bienfaits; avec les prophètes, les véridiques (șiddīīin), les témoins (šuhadā') et les vertueux (șālihīn) : voilà une belle assemblée ! ${ }^{61}{ }^{\prime}$. Ainsi, Ibn Taymiyya affirme que les " plus méritants (afḍal) des hommes, après les prophètes, sont les véridiques (șiddīqūn) ${ }^{62}$. "

De même que pour les états spirituels, le šayh al-islām s'applique à faire la part des choses quant à ceux qui estiment qu'après les prophètes, les hommes les plus méritants sont les soufis, du fait qu'ils ont atteint le degré de șiddìq. Sans contredire l'assertion faisant des soufis les plus méritants des hommes, le savant hanbalite précise que « le soufi n'est qu'un véridique (șiddīq) parmi d'autres classes (naw') de véridiques » et que le degré de șiddīq n'est pas l'exclusivité des soufis.

En présentant le cadre légal des états spirituels et le statut du soufi authentique (șiddīq), Ibn Taymiyya atteste de ce que fut le soufisme « originel ${ }^{63}$ ». Le savant hanbalite distingue trois catégories parmi ceux qui se réclament du soufisme. Il y a tout d'abord les soufis des « réalités métaphysiques » (șüfiyyat al-haqqā’iq), ceux-là mêmes qui ont atteint le degré de șiddīq. Ils sont, selon lui, rares et ne fréquentent pas nécessairement les ḩānqāh. Puis viennent les soufis financés (șūfiyyat al-arzāq), du fait qu'ils bénéficient des fruits des fondations pieuses (wuqūf ou awqāf, sing. waqf). Ces derniers doivent se conformer à trois conditions : le respect de la Loi divine, le respect des règles de la Voie, et le détachement par rapport aux biens de ce monde ${ }^{64}$. Arrivent en dernier lieu, les soufis des « apparences » (șüfiyyat al-rasm), qui n'ont de soufi que le titre.

Cette hiérarchie spécifique aux soufis est relativisée par celle de la Révélation ${ }^{65}$, qui s'applique à l'ensemble du genre humain. Ainsi, les « Amis de Dieu » (awliyā' sing. walī) ne

60. Mağmū' al-fatāwā, vol. XI, p. 18 .

61. Coran 4:69; trad. D. Masson, à l'exception de șiddīqīn et șālihīn que nous avons traduits par « véridiques » et « vertueux ». Cité dans Mağmū' al-fatāwā, vol. XI, p. 17.

62. Ce passage de l'épître vise implicitement la doctrine de la walāya (« sainteté ») de l'école d'Ibn 'Arabī qui, selon la compréhension d'Ibn Taymiyya, prétend à la suprématie du wali (« saint ») sur le nabi (prophète). Sur ce débat et la position d'Ibn Taymiyya, voir CHodKIEWICz 1984a, p. 146-158 ; Laoust 1939, p. 179-203.

63. Iвn TAYmiYya, Mağmū' al-fatāwā, vol. XI, p. 18.

64. Iвn TAYMiYya, Mağmū' al-fatāwā, vol. XI, p. 19.

65. Dans ce cas bien précis, il s'agit du Coran et du hadith qudsī, dit « des actes surérogatoires (nawāfil) », cité par BUHĀēī, Șaḥihh, $81: 38: 2$ (k. al-raqāq) ; IBN TAYMIYYA, Mağmū' al-fatāwā, vol. XI, p. 22-23. Trad. infra, p. 135. Ibn Taymiyya mentionne à trente reprises ce hadith dans les Mağmū' al-fatāwā. Pour l'usage de ce hadith par les auteurs soufis, voir Graham 1977, p. 173-174. Extrait de notre traduction : "Dieu a dit: quiconque montre de l'hostilité à un de «Mes Amis » (walī), Je lui déclare la guerre. Mon serviteur ne s'approche de Moi que par ce que J'aime le plus, par les devoirs religieux que Je lui ai enjoints, puis Mon serviteur ne cesse de se rapprocher de Moi par des œuvres surérogatoires (nawäfil) jusqu'à ce que Je l'aime. Quand Je l'aime, Je suis son oüe par laquelle il entend, sa vue par laquelle il voit, sa main par laquelle il saisit et son pied avec lequel il marche. C'est donc par Moi qu'il entend, qu'il voit, qu'il saisit, et qu'il marche. [...]» 
sont pas exclusivement des soufis, de même que tous les soufis ne peuvent prétendre au statut de wali ${ }^{66}$. Les "Amis de Dieu », selon la Révélation, se distinguent par leurs actes et se répartissent ainsi en deux catégories : les modérés (muqtașidūn) ${ }^{67}$, qu'il dénomme également les compagnons de la droite (așhāb al-yaminn) ${ }^{68}$. Ce sont ceux qui se rapprochent de Dieu par les actes obligatoires (farā’id). Tandis que les rapprochés de Dieu (muqarrabūn) ${ }^{69}$, encore appelés les « devanciers » (sābiqūn) ${ }^{70}$, sont ceux qui se rapprochent de Dieu par les actes obligatoires suivis des actes surérogatoires (nawāfil). Et ce sont ceux-là qui ne cessent de se rapprocher de lui, jusqu'à ce qu'Il les aime, ainsi qu'il est dit dans le Hadīt al-nawāfil.

L'exégèse d'Ibn Taymiyya semble originale dans la mesure où aucun auteur antérieur n'a, à notre connaissance, associé les catégories coraniques des aṣhāb al-yamīn et des muqarrabūn avec les actes obligatoires et les actes surérogatoires dont il est question dans ce hadith qudsī.

D’une manière générale, les exégètes antérieurs à Ibn Taymiyya considèrent le degré des muqarrabūn (Coran 56:11) comme le plus élevé auprès de Dieu, le jour de la résurrection, sans pour autant préciser la manière d'atteindre cette proximité ${ }^{71}$. Dans le Ğāmi al-bayān de Ṭabarī (m. 923) - que par ailleurs Ibn Taymiyya considère comme la plus exacte des exégèses ${ }^{72}$ - muqarrabūn désigne ceux que Dieu rapprochera de Lui le jour de la résurrection (qiyāma) et qu'Il fera entrer au paradis (̌̆anna) ${ }^{73}$.

Àtravers son exégèse, Ibn Taymiyya souligne le double processus qui permet d'atteindre le degré de la proximité divine (qurb) ${ }^{74}$. Il y a, d'une part, la tentative de rapprochement (taqarraba) du serviteur par ses actes et, d'autre part, l'action de grâce du Seigneur, qui fait entrer Son serviteur parmi Ses rapprochés (muqarrabūn) ${ }^{75}$. Pour le savant hanbalite, il s'agit d'une faveur, qui n'est accordée qu'aux croyants, qui craignent Dieu (muttaqūn),

66. Concernant le thème de la walāya (ou wilāya), voir CHodkiewicz 1984c . Sur la réaction d'Ibn Taymiyya contre la doctrine de la « sainteté » (walāya) chez Ibn 'Arabī (m. 1240), voir supra, n. 62.

67. Pour les occurrences de muqtașid, voir Coran $31: 32 ; 35: 32$.

68. Pour așhāb al-yamīn et aṣhāb al-maymana, voir Coran $56: 8,27,90-91 ; 74: 39 ; 90: 18$.

69. Pour muqarrabūn, voir Coran $3: 45 ; 7: 114 ; 26: 42 ; 56: 11,88 ; 83: 21,28$. Nous ne citons pas les versets où muqarrabūn désigne les anges rapprochés de Dieu.

70. Pour sābiqūn, voir Coran $23: 61 ; 35: 32 ; 56: 10$. D. Masson traduit sābiqūn par «les premiers arrivés ». Toutefois, notre choix se base sur le sens de sābiq(ūn), exprimé dans les autres occurrences coraniques, ainsi que sur les différentes exégèses que nous citons ci-après (n. 71), où le terme sābiqūn désigne ceux qui « devancent » les autres croyants dans la foi, la prière, les bonnes actions, etc.

71. Țabarī, Ǧāmi al-bayān, vol. XX, p. 183-184 ; Tálabī, al-Kašf wa-l-bayān, vol. IX, p. 202-203 ; MĀWARDī, al-Nukat wal-'uyūn, vol. V, p. 449 ; IBN 'AṬıYA, al-Muharrar al-wajīz, vol. V, p. 240 ; IBN AL-ĞAwZī, Zād al-masīr, vol. VIII, p. 134 ; RĀZī, Mafātīh al-ġayb, vol. XIX, p. 146-147. Concernant l'opinion d’Ibn Taymiyya à propos des exégètes cités ci-dessus, voir IBN TAYMiYYA, Mağmū' al-fatāwā, vol. XIII, p. 345-385.

72. IBn TAYMiYya, Mağmū' al-fatāwā, vol. XIII, p. 385.

73. ȚABARĪ, Ğāmi al-bayān, vol. XXII, p. 290.

74. Pour l'expérience de la proximité divine chez Harrāz (m. 890), voir NwYIA 1991, p. 252-267.

75. Taqarraba, $V^{\text {e }}$ forme verbale de la racine qrb, implique l'idée d'une recherche «active » de la part du sujet (dans notre cas, le serviteur). Alors que muqarrabūn, participe passif de la $\mathrm{II}^{\mathrm{e}}$ forme verbale, signifie ceux qui sont rapprochés (ici, Dieu rapproche Ses serviteurs de Lui-même). 
qui respectent les obligations religieuses (farā’id) et qui n'agissent que dans le but de se rapprocher de leur Seigneur ${ }^{76}$.

Si l'association du Hadīt al-nawāfil aux versets de la sourate al-Wāqía (Coran 56 : 7-11) semble propre à Ibn Taymiyya, en revanche, l'idée des actes de rapprochement et de la faveur divine existait déjà chez les auteurs classiques du soufisme ${ }^{77}$. Nous retrouvons ce thème dans les propos de Nūrī (m. 907), cités et commentés par Kalābād̄ī (m. 995) :

« Ta proximité ne saurait être le fait de mes attributs ; mais au contraire, s'approcher de Toi ne peut se faire que par Toi et ne provenir que de Toi. [...] des hommes se sont rapprochés ${ }^{78}$ de Toi par leurs œuvres et leurs actes d'obéissance, et Tu ne les as traités avec bienveillance que par pure faveur de Ta part $[. . .]^{79}$."

Le savant hanbalite identifie ainsi les soufis des "réalités métaphysiques » aux rapprochés (muqarrabūn), qu'il assimile par ailleurs à l'élite (hāṣṣ), alors que les modérés (muqtașidūn), identifiés aux compagnons de la droite, représentent le commun des croyants $\left({ }^{(} \bar{a} m m\right)^{80}$.

$\mathrm{Si}$, dans leur grande majorité, les commentaires, traditionnels et mystiques, ne s'attardent pas sur le rapport entre la proximité divine et les actions de l'homme, une seule exégèse, à notre connaissance, semble s'en approcher. Il s'agit des Haqā'iq al-tafsīr ${ }^{81}$ de 'Abd al-Raḥmān al-Sulamī (m. 1021), où les muqarrabūn (Coran 56 :11) désignent « ceux qui rendent le culte le plus sincère à Dieu et qui Lui obéissent par désir et par amour ${ }^{82}$. Dans le supplément à son exégèse (Ziyādāt haqā’iq al-tafsîr ${ }^{83}$ ), Sulamī étoffe le commentaire du verset en question:

«[...] donc celui qui recherche la proximité (taqarraba) de Dieu dans ce monde, doit le rechercher avec un cœur pur (bi-qalb țāhir) et agir avec droiture (bi-'amali hāaliș). À propos des sābiqūn muqarrabūn, certains ont dit que s'ils parlent c'est de Lui (fi-hi) qu'il parlent, s'ils agissent c'est pour Lui (la-hu), s'ils demandent c'est à Lui (min-hu) que s'adressent leurs demandes, s'ils entendent c'est de Lui $(\min -h u)$ qu'ils entendent; ceux-là sont l'élite de Dieu (hāsș̣at Allāh) et du nombre de Ses intimes (ahl al-wilāyati-hi). Ibrāhīm al-Hुawwāṣ ${ }^{84}$ a dit : ce sont ceux qui se hâtent vers Lui (bādirū ilay-hi) et s'empressent d'agir avec zèle dans ce qu'ils visent. Ils attestent de Son unicité (wahhada-hu) dans leurs cœurs (damā’ir). Ils se

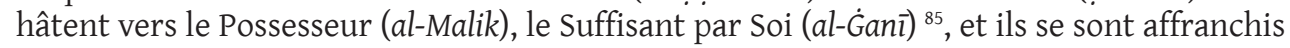

76. IBn TAYMiYyA, Mağmū' al-fatāāwa , vol. XI, p. 22-23.

77. L'idée de ces « deux degrés de la vie spirituelle »-d'une part, l'observance des obligations religieuses par le serviteur ('ibāda), et d'autre part, l'action de la grâce divine (minna) envers son wali - est également exprimée par Tirmidī (m. 898) dans son Kitāb hatm al-awliyā'. Voir CHoDKIEWICZ 1984c, p. 44-45.

78. Le verbe utilisé est : taqarraba.

79. KALĀBĀD̄ī, Traité de soufisme, p. 118.

80. Iвn TAYмiYyA, Mağmū' al-fatāwā, vol. X, p. 6-7.

81. À propos de cet ouvrage majeur de Sulamī, voir THiBon 2009, p. 396-404.

82. «[...] wa 'abadū-hu bi-'ahlaș al-'ibāda wa-inqādū ilay-hi bi-l-šawq wa-l-mahhaba », extrait de Sulamī, Haqā’iq al-tafsīr, vol. II, p. 300. Il s'agit d'une édition non critique signalée (mais non évaluée) par Thiвon 2009, p. 396, n. 625.

83. Voir ThiBon 2009, p. 404-406.

84. Ibrāhīm al-Hुawwāṣ (m. 904), voir ABŪ NU' AYm AL-IșBAHĀNī, Hilyat al-awliyā', vol. X, p. 225-231.

85. Gloton 2007, p. 28 et p. 201. 
de l'asservissement et des causalités de ce monde (wa a'taqū anfusa-hum min raqq al-ḩalq wa asbāb al-duniyā) ${ }^{86}$. »

L'opinion générale d'Ibn Taymiyya sur le Haqā’iq al-tafsìr est mitigée, estimant que si le signifié (madlūl) reste valide, en revanche, l'argument (dalīl) est erroné ${ }^{87}$. Par ailleurs, il souligne qu'une partie des Haqā'iq se base sur des chaînes de transmission faibles, notamment celles remontant à Ğafar al-Ṣādiq (m. 765) ${ }^{88}$. Ibn Taymiyya n'admet pas l'authenticité des propos attribués à l'imam chiite, et pense qu'il s'agit des dires de Sulamī lui-même. Une autre critique vise les erreurs concernant les transmetteurs, tout en admettant que les propos transmis sont corrects. Pour le reste, les interprétations restent valables tant qu'elles ne contredisent pas le Coran ou la Sunna ${ }^{89}$.

Il semblerait par conséquent que la conception de la proximité divine d'Ibn Taymiyya, ainsi que sa hiérarchie spirituelle, soient inspirées de l'œuvre de Sulamī. Ainsi, le « signifié » (madlūl) tiré des Haqāiqq, est transposé dans le cadre de sa doctrine des trois fondements de l'islam, moyennant un dalīl irréfutable : le hadith qudsī des actes surérogatoires (nawāfil).

\section{CONCLUSION}

$\mathrm{Au}$ vu des écrits du šayh al-islām, il nous semble désormais malaisé de voir en lui l'ennemi acharné du soufisme. Ses griefs ne visent en réalité que certaines formes de la mystique, jugées déviantes ${ }^{90}$. Ses réactions, souvent virulentes, s'expliquent notamment par son interprétation du contexte sociopolitique. En effet, l'instabilité politique ${ }^{91}$, la " crise morale et religieuse ${ }^{92}$, la passivité des oulémas ${ }^{93}$, les périls extérieurs ainsi que le danger représenté par les minorités « rebelles » ${ }^{94}$, menacent, selon lui, la religion de Dieu, enseignée et vécue par le prophète de l'islam.

La «translation temporelle » vers l'âge d'or de l'islam lui permet d'une part d'exposer ce que fut la mystique idéale, celle du Prophète, des Compagnons et des Suivants, et d'autre part de poser le cadre juridique incontestable de ses fatwa.

Les griefs du savant hanbalite envers certaines doctrines et pratiques du soufisme s'inscrivent dans le cadre d'un réformisme religieux visant à débarrasser la šarî́a et le tașawwuf, corps et cœur de l'islam, de ses innovations et de ses "exagérateurs».

86. Traduit à partir du texte arabe dans Sulamī, Ziyādāt haqā’iq al-tafsīr, p. 192-193.

87. Iвn TAYмiyya, Mağmū' al-fatāwā, vol. XIII, p. 362.

88. Pour les sources de Sulamī, voir BöWERIng 1996 ; ThiBon 2009, p. 405, n. 681.

89. Iвn TAYмiyya, Mağmū' al-fatāwā, vol. XIII, p. 242-243.

90. Voir supra, n. 4.

91. Un aperçu de l'organisation de l'État mamelouk et de la rivalité entre émirs est donné dans GARCIN 1995, p. 343-352.

92. De son propre aveu, c'est pour répondre à ces problèmes qu'il entreprit, vers 1299, la rédaction de sa profession de foi Wāsițiyya, à la demande du cadi chaféite de Wāsiț qui « se disait inquiet de l'état d'ignorance dans lequel les autorités mongoles laissaient les populations musulmanes d'Irak », cité dans IBN TAYMIYYA, La profession de foi d'Ibn Tamiyya, p. 14. Sur son réformisme en général, voir LAoust 1962. Sur les polémiques autour de la conversion à l'islam du souverain mongol Ġāzān Hुān (r. 1295-1304), voir Aigle 2008.

93. Ibn Taymiyya juge contreproductif le rigorisme des fuqahä’. En effet, leur interprétation de la loi est si rigide, selon lui, qu'ils s'obligent à la contourner par des subterfuges juridiques. Voir Laoust 1962, p. 29.

94. Pour l'effort de guerre mamelouk, voir Garcin 1995, p. 352-354 ; Amitai-Preiss 1995, p. 214-235 ; Aigle 2008, p. 1-4. 
L'acharnement dont il fit preuve dans la réhabilitation de la pensée mystique fut sans doute à la hauteur de la mission qu'il estimait être sienne :

« Dieu fera [cependant], immanquablement, surgir dans cette [religion], successivement aux Messagers, des gens par qui [Son] argument (huğğa) sera notifié et qui débarrasseront des falsifications des exagérateurs, des prétentions (intiḥāl) des substituteurs et des interprétations des ignorants ${ }^{95}$. »

Dans L'épître des soufis, le šayh al-islām s'efforce de montrer que le terme tașawwuf, loin d'être une appellation sans réalité, désigne une science islamique à part entière, au même titre que le figh. Le soufisme implique, selon lui, «la gnose (ma'ârif), les états spirituels ( $a h w w \bar{a} l)$, les bonnes mœurs (ahlāa), les règles de bienséance (ādāa), etc. ${ }^{96}$. Le soufisme, ou la science des états spirituels ${ }^{97}$, a pour finalité de conduire, progressivement, le « cheminant » au degré de la proximité divine (qurb). 'Imād al-Dīn al-Wāsițī (m. 1311), le disciple qu'Ibn Taymiyya avait initié à la lecture du hadith, affirme en effet que la voie pour atteindre cette proximité divine n'est autre que l'imitation (mutāba'a) du Prophète ${ }^{98}$, dans ses œuvres extérieures comme dans ses états spirituels ${ }^{99}$. Voilà pour ce qui est de la quintessence du soufisme selon Ibn Taymiyya. Son aspect éthique ne diffère pas de celui des mystiques et des traditionalistes primitifs : «ordonner le bien et interdire le blâmable ».

Quant à sa méthode d'exégèse, il s'agit probablement d'un procédé de "mise en conformité » des grands thèmes du soufisme avec les trois sources fondamentales de « son sunnisme ${ }^{100}$ ». Si cette hypothèse se voyait confirmée, l'œuvre du šayh al-islām serait alors à considérer selon une double perspective : la réhabilitation des sciences ésotériques, dans le dessein d'une revivification du sunnisme en mal de sens ${ }^{101}$.

Un autre élément en faveur d'une telle hypothèse réside dans sa généralisation des thèmes du soufisme à l'ensemble des croyants. Il affirme que la doctrine des stations et des états spirituels (al-maqamāt wa-l-ahwāl), - qu'il nomme également les actes du coeur ( $a^{\prime} m \bar{a} l$ al-qulūb) - fait partie des fondements de la foi et des bases de la religion (min ușūl al-ìmān wa qawāi id al-dīn). Par conséquent, cette doctrine s'applique obligatoirement à l'ensemble des hommes ( $f a$ aqūlu : hādihi al-a'māl ğamî́u-hā wāğiba 'alā ğamí al-hnalq). Il ajoute que les actes extérieurs (zāhir) de la dévotion n'ont aucune utilité sans les actes intérieurs (bāțin), car les aspects ésotériques des sciences et des actes (al-umūr al-bāțina min al-ulūm wa-l-a'māl) représentent le véritable fondement de la religion.

95. Iвn TауміYүa, Mağmū' al-fatāwā, vol. XI, p. 435 ; trad. Мıснот 2007, p. 57.

96. Iвn TAYмiYYA, Mağmū' al-fatāwā, vol. XI, p. 21.

97. Sur la doctrine des « stations et états spirituels » (al-maqamāt wa-l-ahwwāl), voir GARDET et ANAWATI 1976, p. 41-43;

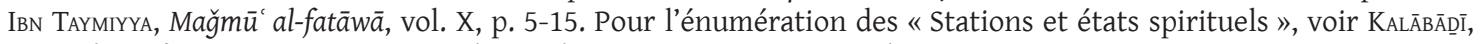
Traité de soufisme, p. 91-161; AnșĀRī, Chemin de Dieu : trois traités spirituels, p. 86-150.

98. Pour les soufis, le Prophète incarne le modèle parfait du maître spirituel, en qui s'équilibrent l'exotérique et l'ésotérique. Voir GRIL 1996c, p. 29.

99. GeofFroy 1995b, p. 89.

100. Rôle qui fut attribué à ĠAZĀLİ (m. 1111) par l'orientalisme du XIx siècle.

101. Voir Iвn TауміYya, Mağmū' al-fatāwā, vol. X, p. 5-15. Par ailleurs, il affirme que, selon les ahl al-sunna wa-l-ğamā'a, « la religion ( $\operatorname{din})$ et la foi ( $\bar{m} m \bar{a} n)$ consistent en paroles et en actes : en paroles du cœur et de la langue, en actes du cœur, de la langue et des membres », (voir IBn TAYмiYya, La profession de foi d'Ibn Tamiyya, p. 73). 
Bien que destinée à un large public, L'épittre des soufis dévoile les grandes lignes de la doctrine mystique du šayh al-islām. Sainteté et prophétie, šarīa et țarīqa, cheminement initiatique et grâce divine, l'élite et le commun, etc., autant de thèmes qu'Ibn Taymiyya détaille par ailleurs et qui mériteraient, selon nous, une investigation plus approfondie.

L'ÉPÎTRE DES SOUFIS ET DES «PAUVRES EN DIEU » ${ }^{102}$

[5] De par le nom de Dieu : Celui qui fait miséricorde, le Miséricordieux.

Louange à Dieu seul. Prière et salut sur celui après qui il n'y a point de prophète. Le šayh al-islām - que Dieu sanctifie son âme - fut interrogé au sujet des soufis (șūfiyya) ${ }^{103}$. Ils sont [de plusieurs] sortes (aqsām), et il en est de même pour les « pauvres en Dieu » (fuqarā'). Par conséquent, quelle est la particularité de chaque fraction (qism) ? Quelle obligation incombe à chacune d'elles et quelle voie doit-elle suivre de préférence (yastahibbu) ${ }^{104}$ ?

Il répondit :

Louange à Dieu. Quant au terme șūfiyya, il n'était pas répandu dans les trois premières générations [de l'islam] (qurūn) ${ }^{105}$, mais cela s'est produit par la suite. Il a été rapporté que plus d'un imam et plus d'un maître (šayh) l'ont employé, tels l'imam Ahmad Ibn Hanbal ${ }^{106}$, [le šayh] Abū Sulaymān al-Dārān̄̄i ${ }^{107}$ et bien d'autres. Il est rapporté que Sufyān al-Tawrīī 108 fit usage de ce terme alors que d'autres mentionnent cela à propos de Ḥasan al-Bașrīi ${ }^{109}$.

102. La présente traduction a été réalisée à partir du texte arabe lu dans IBN TAYмIYYA, Mağmū' al-fatāwāa p. p- 5-23. Les chiffres souscrits entre crochets renvoient aux pages de cette édition. Pour une traduction en langue anglaise du même passage voir HoMERIN 1985, p. 221-237. Notre travail se voulant complémentaire à celui de Homerin, nous renverrons le lecteur vers les notes de ce dernier pour ce qui est des divergences entre les différentes éditions de cette épître, ainsi que pour la plupart des références bibliographiques concernant les personnages cités. Notre traduction reste dans l'ensemble conforme à cette dernière, cependant, nous estimons que certains choix opérés par Homerin peuvent mener à des contresens, notamment sur des points essentiels de la doctrine d'Ibn Taymiyya ; points que nous signalerons dans nos notes. Pour les versets coraniques, nous nous sommes référés à la traduction de D. Masson, toute variation par rapport à cette dernière étant signalée en note.

103. Les questions qui suivent laissent, d'une part, penser qu'il existait à l'époque d'Ibn Taymiyya une multitude de voies mystiques et, d'autre part, des interrogations quant à l'authenticité de ces voies. La richesse du tissu ascétique et mystique, dans la région de Damas, est signalée par Pouzet 1991, p. 207-243. Sur les « Grands courants du tașawwuf dans le domaine syro-égyptien » à l'époque mamelouke, voir GEofrroy 1995a, p. 205-239.

104. Le verbe yastahibbu est à comprendre dans le sens de « ce qui est recommandable ».

105. L'expression « al-qurūn al-țalāta » désigne les trois premières générations après le Prophète. Homerin a opté pour « les trois premiers siècles », ce qui, selon nous, est un contresens. La suite du texte ainsi que d'autres passages du Mağmū' al-Fatāwā nous confortent dans notre choix. Voir nos remarques à ce sujet supra, p. 114-115.

106. À propos d'Ibn Ḥanbal (m. 855) et les « soufis », voir Melchert 2006, p. 103-120.

107. Abū Sulaymān al-Dārānī (m. 830) fait partie de la deuxième génération de disciples de Hasan al-Bașrī (m. 728). Avec Dārānī le mouvement «mystique » instauré à Bassora s'étend à Damas. Il est l'auteur d'une des premières esquisses de la doctrine des stations spirituelles (maqāmāt), voir GARDET et ANAWATI 1976, p. 27. Autres références bibliographiques dans Homerin 1985, p. 221, n. 13.

108. Sufyān b. Sa īd al-Tawrī (m. 778), un traditionniste de Coufa. Voir également références dans HomERIN 1985, p. 221, n. 14.

109. Hasan al-Bașrī (m. 728) faisait partie de la génération des «Suivants» (tābi ūn). Considéré comme le " patriarche de la mystique musulmane », il figurera plus tard quasi systématiquement dans les chaînes initiatiques 
Il y eut divergence à propos de la signification ${ }_{[6]}$ attribuée au terme șūfĭ ${ }^{110}$. Il s'agit en réalité d'un adjectif d'attribution, tels qurašī, madan̄i, etc.

On a avancé que le terme se rapportait aux «gens du banc» (ahl al-șuffa). Ceci est erroné, car s'il en avait été ainsi, on aurait dit șuffiyy. De même qu'il est erroné d'attribuer l'origine du terme șūfì au « rang (șaff) avancé qui se tient devant Dieu » ou bien à « l'élite (șafwa) de la création de Dieu ${ }^{111}$ ». S'il en avait été ainsi, on aurait dit șaffiyy ou bien șafawiyy. On a prétendu que le terme șūfì se rapportait à Șufa b. Bišr b. Addi b. Țābiha, une tribu arabe qui dans l'ancien temps habitait dans les environs de La Mecque et à laquelle on rattache (yunsabu ilay-him) des ascètes (nussāk) ${ }^{112}$. Si d'un point de vue lexical cela semble acceptable, en revanche l'argument est faible, car cette tribu n'était point célèbre et la plupart des ascètes ne la connaissaient pas. Et si les ascètes étaient rattachés à cette tribu, [ce rattachement] aurait été encore plus probant à l'époque des Compagnons, des Suivants et de leurs successeurs [immédiats]. De plus, la majorité de ceux qui se disaient soufis ne connaissaient pas cette tribu et n'auraient jamais admis la filiation à une tribu antéislamique, n'existant plus à l'époque dont il est question.

Il est dit - et cela est connu - que [le terme] șūfì se rapporte au port d'un [habit] de laine.

En fait, les soufis sont apparus pour la première fois à Bassora et les premiers à avoir bâti un « cloître » soufi (duwayra) ${ }^{113}$ furent certains disciples (așhāab) de 'Abd al-Wāhid b. Zayd ${ }^{114}$; celui-ci faisait partie des disciples d'al-Hasan [al-Bașrī].

Il y avait à Bassora une certaine exagération, dans le renoncement (zuhd), la dévotion ('ibāda), la crainte de Dieu (hawf), ainsi que sur d'autres sujets ${ }_{[7]}$ que l'on ne trouvait pas chez les habitants des autres métropoles (amșār). C'est pourquoi il était d'usage de dire : la jurisprudence selon [les gens de] Coufa et la dévotion selon [ceux de] de Bassora ${ }^{115}$. D'après sa chaîne de transmetteurs remontant à Muhammad b. Sīrīn ${ }^{116}$, Abū-l-Šayh al-Ișbahānī ${ }^{117}$ a rapporté que ce dernier avait mentionné un groupe (qawm) ayant préféré des habits de laine, selon les termes suivants : "c'est un groupe qui a opté pour [l'habit de] laine, prétendant imiter le Christ fils de Marie. Cependant, l'exemple (hady) de notre prophète, qui s'habillait

soufies. Voir GARDEt et ANAWATI 1976, p. 24-26; RITTER 1970 ; MouRAD 2006. Références supplémentaires dans HomERIN, 1985, p. 221, n. 15.

110. Sur l'origine, l'utilisation et l'évolution de l'appellation individuelle (șūfî) ou collective (șūfiyya) voir MASSIGNON 1999, p. 153-156.

111. Ahl al-șuffa, șaff et șafwa sont également évoqués dans KALĀBĀD̄Ī, Traité de soufisme, p. 25-31. Autres références dans HOMERIN 1985, p. 222, n. 16, 17 et 18.

112. Cette origine n'est pas citée par les auteurs soufis classiques, mais figure chez Ibn al-Ǧawzī, voir HomERIN 1985, p. 222, n. 19. Dans la suite du texte, nous avons convenu de traduire nussāk par « ascètes », zuhhād par « renonçants » et 'ubbād par « dévots».

113. C'est-à-dire « l'agglomération cénobitique » d'Abbādān, voir MAssignon 1999, p. 214.

114. 'Abd al-Wāhiid b. Zayd (m. 793), disciple de Hasan al-Bașrī, est considéré comme le « maître » d'Abū Sulaymān al-Dārānī. À propos de 'Abd al-Wāhịid, voir ABū Nứ AYM AL-IṣBAHĀnī, Hillyat al-awliyā', vol. 6, p. 155-165.

115. Sur les origines du soufisme voir Melchert 1996 ; Karamustafa 2007.

116. À propos de Muhammad b. Sīrīn (m. 728) et la condamnation des états d'extase artificielle, voir MAsSIGNON 1999, p. 153, 197-198. Autres références bibliographiques dans HOMERIN 1985, p. 223, n. 21.

117. Abū Nu'aym al-Iṣbahānī (m. 1038), l'auteur de Hilyat al-awliyā'. 
de coton et d'autres [sortes de tissus], nous est préférable ». Il y eut également d'autres histoires de ce genre.

C'est pourquoi la plupart des choses que l'on raconte concernant l'exagération dans ce domaine ne se rapportent qu'aux dévots ('ubbād) de Bassora. À l'exemple de l'histoire de celui qui mourut ou qui perdit connaissance lors de l'audition du Coran ; comme l'histoire de Zurāra b. Awfā, le juge de Bassora ${ }^{118}$, qui tomba raide mort alors qu'il récitait, lors de la prière du matin, le verset : \{Lorsque l'on sonnera de la trompette\} ${ }^{119}$ (Coran $74: 8$ ). Ou bien l'histoire d'Abū Ǧahīr al-A'mā qui mourut, alors que Șālih al-Murrī̄ ${ }^{120}$ lui récitait le Coran. Et ainsi, on rapporte d'autres histoires à propos de ceux qui moururent à l'audition du Coran. D’autres parmi [les gens de Bassora] étaient « foudroyés » (yușaqūna) ${ }^{121}$ lors de la récitation du Coran. Cependant, les Compagnons ne connurent point cet «état spirituel » (hâl). Par conséquent, lorsque de tels phénomènes apparurent, une partie des Compagnons et des suivants les désavouèrent, tels Asmā' la fille d'Abū Bakr, 'Abd Allāh b. al-Zubayr ${ }^{122}$, Muhammad b. Sīrīn et d'autres.

La réprobation se fit de deux manières :

Il y avait ceux qui pensaient qu'il ne s'agissait que de feinte et de simulation. Ainsi, il est mentionné que Muhammad b. Sīrīn a dit : «Ce qui permettra de trancher entre nous et ceux qui sont foudroyés (yușaqūna) lors de l'audition du Coran, c'est [l'épreuve suivante] : celui qui tombe (harra) lors de la récitation du Coran, ${ }_{[8]}$ tandis qu'il est placé [en hauteur] sur un mur ('alā ḥ̂a'it), alors celui-ci est sincère ".

Et parmi les réprobateurs, il y avait ceux qui désavouèrent ceci ${ }^{123}$ [totalement] car ils y voyaient une innovation contraire à l'exemple (hady) des Compagnons, ainsi qu'il est mentionné à propos de Asmā' et de son fils 'Abd Allāh.

L'opinion de la majorité des oulémas est que celui qui est touché [par un tel état], alors qu'il est dans l'incapacité [de le repousser], ne peut être blâmé. Néanmoins, [ces oulémas estiment] qu'un état inébranlable (hāl al-tābit - sic) lui est préférable. À cet effet, lorsque l'imam Ahmad [b. Hanbal] fut interrogé à ce sujet, il répondit : «Yahyā b. Sa īd al-Qatțān ${ }^{124}$ perdit connaissance tandis qu'on lui récitait le Coran. S'il y avait bien eu quelqu'un capable de «repousser » [un tel état], cela aurait été Yahyā. En effet, je n'ai vu personne plus raisonnable (a'qal) que lui ». D'autres histoires de même sorte sont rapportées. On raconte que [l’imam] Šăfi'î fut [également] touché par un tel [état] ${ }^{125}$. Ce fut également le cas de

118. Zurāra b. Awfā (m. vers 713). Selon Homerin, la précision de la fonction de Zurāra évite toute confusion avec son homonyme, compagnon du Prophète. En effet, plus loin, Ibn Taymiyya affirme que de tels états n'étaient pas arrivés aux Compagnons. Voir Homerin 1985, p. 223, n. 22 et p. 239, n. 61, 62 et 63.

119. Traduction de D. Masson.

120. À propos de Șālih al-Murrī (m. 793), voir Homerin 1985, p. 223, n. 23.

121. Traduction basée sur le passage coranique où Moïse tombe «foudroyé » (Coran $7: 143)$. Autre traduction possible : «terrassé ».

122. À propos d'Asmā' bint Abū Bakr et de son fils 'Abd Allāh b. al-Zubayr, voir Homerin 1985, p. 224, n. 24 et 25.

123. C'est-à-dire le fait de tomber mort ou de perdre connaissance lors de l'audition du Coran.

124. À propos de Yahyā b. Sa īd al-Qațtān (m. 813), voir Homerin 1985, p. 224, note 28.

125. Rapporté par Ġazālī (m. 1111), voir HoMERIN 1985, p. 224, note 29. 
'Alī b. Fuḍayl b. 'Iyāḍ ${ }^{126}$, dont l'histoire est célèbre. En bref, [cet état spirituel] est arrivé à beaucoup, dont on ne peut mettre en doute la sincérité.

Cependant, les états spirituels (ahwāl) atteints par les Compagnons sont ceux mentionnés dans le Coran : le frémissement des cœurs, le frissonnement des peaux et les larmes aux yeux, ainsi que le Très-Haut l'a mentionné :

«\{Seuls, sont vraiment croyants : ceux dont les cœurs frémissent à la mention du Nom de Dieu; ceux dont la foi augmente lorsqu'on leur récite ses Versets ; - ils se confient en leur Seigneur. - (Coran $8: 2$ ). \{Dieu a fait descendre le plus beau des récits : un Livre dont les parties se ressemblent et se répètent. La peau de ceux qui redoutent leur Seigneur en frissonne, puis leur peau et leur cœur s'adoucissent à l'invocation du nom de Dieu.\} (Coran $39: 23$ ). \{Ils tombaient prosternés en pleurant quand les Versets du Miséricordieux leur étaient communiqués.\} (Coran 19:58). \{Tu vois leurs yeux déborder de larmes lorsqu'ils entendent ce qui est révélé au ${ }_{[9]}$ Prophète, à cause de la Vérité qu'ils connaissent en lui.\} (Coran $5: 83$ ). \{Ils tombent sur leurs faces en pleurant ; leur humilité augmente.\} (Coran $17: 109)$.»

L'état spirituel de ceux-là ${ }^{127}$ est condamné par ceux dont les cœurs sont endurcis (qiswa) et couverts d'impuretés (rayn), et qui ont de l'aversion ( $\breve{a} a \bar{a}^{-}$) envers la religion ; [en réalité] ce sont leurs propres états qui sont répréhensibles. Alors que d'autres estiment que leur état [extatique] est le plus parfait. Ils pensent ainsi avoir parachevé les états spirituels et en avoir atteint les plus hauts degrés. Ces deux positions extrêmes sont blâmables.

Cependant, on distingue trois degrés ${ }^{128}$ [dans les états spirituels de ceux qui s'adonnent à l'audition du Coran] :

Le premier de ces degrés, c'est l'état spirituel de celui qui est injuste envers lui-même (al-zālim li nafsi-hi). Son cœur est endurci et ne s'adoucit point à l'audition du Coran ou à l'invocation [du nom de Dieu] (ㅁikr). Celui-là est, en certains points, semblable aux « Juifs » [qui furent avec Moïse] ${ }^{129}$. Ainsi que Dieu l'a dit :

«\{Vos cœurs, ensuite, se sont endurcis. Ils sont semblables à un rocher, ou plus durs encore. Il en est, parmi les rochers, d'où jaillissent les ruisseaux ; il en est qui se fendent, et l'eau en sort ; il en est qui s'écroulent par crainte de Dieu. - Dieu n'est pas inattentif à ce que vous faites-\} (Coran $2: 74$ ). \{Le moment n'est-il pas venu pour les cœurs des croyants de s'humilier en entendant le Rappel de Dieu et ce qui est descendu de la Vérité et de ne plus ressembler à ceux qui avaient autrefois reçu le Livre ? Ceux-ci trouvèrent le temps long ; leurs cœurs s'endurcirent. Beaucoup d'entre eux étaient des pervers.\} (Coran 57 : 16). »

Le deuxième degré, c'est l'état spirituel du croyant pieux (taqiyy), qui comporte une certaine faiblesse à supporter ce qui peut atteindre (yaridu) son cœur. C'est celui-ci qui

126. 'Alī b. Fuḍayl b. 'Iyāḍ (m. avant 803), un court passage sur son décès dans Massignon 1999, p. 173. Pour les sources, voir Homerin 1985, p. 224, note 30.

127. Ceux qui, lors de l'audition du Coran, subissent les états de « foudroiement », de la perte de connaissance, etc.

128. Seuls deux des trois degrés sont cités explicitement, le troisième degré dans les états spirituels est celui des Compagnons. Ces trois degrés, omniprésents dans l'œuvre d'Ibn Taymiyya, proviennent de Coran (35:32): zālim li-nafsi-hi, muqtașid et sābiq bi-l-h̆ayrāt ; verset qu'il cite en toute fin de L'épittre des soufis. Voir infra, p. 136.

129. Les compagnons de Moïse auxquels Dieu s'adresse dans ce verset. 
meurt ou bien qui perd connaissance après avoir été foudroyé. Cet [état] ${ }_{[10]}$ est dû à la puissance de « l'inspiration subite » (wārid) ${ }^{130}$ ainsi qu'à l'incapacité du cœur à la supporter.

Il en est parfois de même pour celui à qui le bas monde procure [indistinctement] joie, peur, tristesse ou bien attachement. En effet, ce [vacillement] le mènera soit à la mort, soit à la maladie ou bien à la folie. Ainsi, parmi les idolâtres des formes ('ubād al-șuwar) ${ }^{131}$, il y a celui que l'amour passionnel ('išq) a conduit à la maladie, à la mort ou bien à la folie. Et ainsi de suite. [Cet état] ne peut survenir qu'à celui dont l'âme ainsi affaiblie est inapte à le repousser ou bien à celui qui en est submergé (mag்lūb) ${ }^{132}$, à l'instar du corps, qui est atteint par ce qui le conduit à la maladie ou à la mort.

Celui qui est atteint par un tel [phénomène], alors qu'il n'a commis ni négligence (tafrìt) ni transgression ('udwān), ne peut être considéré comme responsable (danb); et on ne doit pas douter de son état. Et il en est ainsi pour celui qui écoute le Coran, selon les convenances légales, et qui ne néglige rien de ce qui est requis dans ce domaine.

Et il en est de même pour les cœurs qui sont atteints par ce qui est appelé l'ivresse spirituelle (sukr), l'extinction mystique ( $\left(\mathrm{fan} \bar{a}^{\prime}\right)^{133}$, ou bien par toute autre chose se rapportant à la perte du discernement, contre la volonté de celui qui vit l'état spirituel. Par conséquent, si la cause [d'un tel phénomène] n'est pas proscrite (maḩzūr), «l'extatique » (sakrān) n'est pas condamnable (madmūm), mais excusé ( $m a \underline{d} \underline{d} \bar{u} r)$, car ce dernier est sans discernement.

Par ailleurs, on est arrivé à [l'état d'ivresse] par la consommation d'enivrants, tels le hamr (boissons enivrantes) et le haschich ${ }^{134}$. Or, ceci est, sans conteste, considéré comme illicite par les musulmans. Celui qui estime licite l'ivresse par le biais des enivrants est un infidèle (kāfir).

L'ivresse peut [également] être causée par l'amour et la passion des formes, ainsi qu'il est dit :

Des deux ivresses, celle de la passion et celle du vin.

130. Définition proposée par Kasimirski : «Inspiration subite, idée qui surgit spontanément dans l'esprit ». E. Geoffroy signale une synonymie entre wārid et hāl chez Ibn 'Arabī. Ce dernier mentionne trois types de réaction vis-à-vis du wārid : celui qui en devient fou, celui qui en est temporairement submergé et celui qui maîtrise son état. Voir GEOFFroy 1995a, p. 316.

131. 'Ubād al-șuwar: il s'agit probablement de ceux qui s'adonnaient à la contemplation de jeunes garçons imberbes. Voir nos remarques, supra, p. 113.

132. Kalābād̄ī emploie également le terme « emprise » (g்alaba). Voir KALĀBĀD̄ī, Traité de soufisme, p. 126-128.

133. Selon Ibn Taymiyya « l'extinction mystique (fan $\vec{a})$ est de trois genres. [Il y a premièrement le fan $\bar{a}$ ] de ceux qui, parmi les Prophètes et les Amis de Dieu (awliy $\left.\bar{a}^{\prime}\right)$, ont atteint la perfection. [Puis vient le fana $\bar{a}^{\prime}$ de ceux d'entre les Amis de Dieu et les Vertueux qui cheminement (qāșidìn) [vers cette perfection]. [Vient en dernier lieu, le fanā'] des hypocrites impies (mulhidīn) et assimilationnistes (mušabihīn) », cité dans IBN TAYмiYya, Mağmū' al-fatāwāa, vol. X, p. 218.

134. Hamr désigne aussi bien le vin que les boissons enivrantes en général. Le contexte de l'épître laisse penser qu'il s'agit d'une appellation générique pour l'ensemble des boissons conduisant à l'état d'ivresse. Pour la suite du texte nous emploierons le terme hamr sans le traduire. Sur la condamnation des enivrants par Ibn Taymiyya, voir Міснот 2001a, p. 79. 
À quand le désenivrement de celui qui en est doublement ivre ? ${ }^{135}$

${ }_{[11]} \mathrm{Et}$, ceci est condamnable car la cause en est illicite.

D'autre part, l'ivresse peut être occasionnée par l'audition des «voix ravissantes » (al-așwāt al-muțriba) ${ }^{136}$, ceci est également condamnable, car il n'est pas autorisé à un homme de s'adonner à l'audition de «chants» (așwāt) qui n'a pas fait l'objet d'une prescription [légale], et qui conduit à la perte du discernement, cette dernière étant considérée comme illicite. En effet, il est illicite d'aboutir à [l'ivresse] par des moyens illégaux. [La même condamnation s'applique à] ce qui survient lors de cette [expérience], qu'il s'agisse d'un plaisir émotionnel (ladd da qalbiyya) ou bien spirituel (laddda rūhiyya), et ce même si les causes [à l'origine de cet état], contiennent des éléments de foi ; car [ces éléments de foi] sont rendus caducs (maġmūra) par [l'interdiction générale relative à] la perte du discernement. En effet, Dieu ne nous a pas autorisé la jouissance du cœur ou de l'esprit par le biais des plaisirs de la foi, ni par d'autres biais, lorsque ceux-ci entraînent nécessairement la perte de notre discernement.

À l'inverse, cet état n'est pas condamnable, si la cause en est licite (mašrū ), ou bien si elle survient de manière accidentelle et que celui qui en est victime ne peut le repousser. En effet, l'ivresse spirituelle peut survenir sans que le serviteur ait cherché à la provoquer, à l'exemple d'une audition fortuite (samā' lam yaqșid-hu) ${ }^{137}$, déclenchant ses émotions endormies [jusque-là] (yuharriku sākina-hu). Ou bien dans d'autres cas similaires. Dans ce cas, nul blâme (malām) sur [l'extatique], ni sur ce qui peut émaner de lui [comme paroles] alors qu'il est dans un état d'absence de discernement ${ }^{138}$. Par conséquent, il est excusable. En effet, Dieu ne demandera pas compte à ceux qui ont perdu le discernement, pour des raisons qui ne sont pas jugées illégales, tels le comateux, le fou, etc.

Quant à celui qui a perdu tout discernement, suite à la consommation de hamr, estil responsable de l'état auquel il a abouti ? Il y a, à ce sujet, deux débats célèbres. Il y a [,d'une part,] la fameuse divergence à propos de celui qui prononce la répudiation (țalāq) en état d'ébriété ${ }^{139}$; [Et, d'autre part, la controverse] concernant celui qui a perdu tout discernement suite à la consommation de banğ ${ }^{140}$. Selon certains hanbalites et chaféites, ce cas relève de la même disposition [légale] que le hamr. En revanche, Ibn Ḥanbal [lui-même]

135. Vers cités par QUŠAYRĪ, Risāla, vol. 1, p. 176-177. Références supplémentaires dans HomERIN 1985, p. 227 , n. 33. Autre traduction, proposée par Michot : « Il y a deux ivresses : l'ivresse d'une passion et l'ivresse d'un vin. Quand donc se dégriserait celui qui, d'une double ivresse, est atteint? », cité par Мıснот 2001b, p. 171.

136. « Le tarab est pour Ibn Taymiyya, dans le Livre du Samâ et de la Danse, une situation de jouissance provoquée par instrument, voix, boisson, plaisir et qui peut mener, quand elle est particulièrement forte à une absence du sujet », cité par Мıснот 1991, p. 42. Pour la traduction de «al-așwāt al-muțiba », voir ibid., p. 108.

137. À propos du samāc fortuit voir Мıснот 1991, p. 96-97, n. 7.

138. Cette assertion permet d'excuser les locutions théopathiques (šațahāt) de certains soufis, voir supra, p. 115.

139. Nous savons par ailleurs qu'Ibn Taymiyya rejette la validité de la réunion des trois répudiations (țalāq) en une seule, s'inscrivant ainsi en faux contre l'opinion majoritaire de son école. Voir nos remarques, supra, p. 113.

140. Le banğ, assimilé à la marijuana par Homerin, « désigne habituellement la jusquiame, une plante herbacée vénéneuse dont on tirait calmants et narcotiques », voir Мıснот 2001a, p. 79, note 1. 
et l'école hanafite font une distinction entre le banğ et le hamr, car seul ce dernier donne lieu à une addiction. C'est pourquoi ${ }_{[12]}$ [seule] la consommation du hamr aboutit à la sanction légale (hadd).

La puissance de "l'inspiration subite » (wārid) a conduit certains parmi ceux [qui ont été mentionnés] à la folie (mağnūn) ${ }^{141}$. Soit de par la confusion qui s'est emparée d'eux, soit pour d'autres raisons. Les « sages » parmi ces fous ('uqalä'al-mağāninn), que l'on compte parmi les ascètes (nussāk), sont parfois appelés les « ravis en Dieu » (muwallahūn) ${ }^{142}$. À leur propos, certains savants ont affirmé qu'à ceux-là, Dieu a donné la raison et les états spirituels ; puis il leur a ravi la raison, ainsi tombèrent les obligations [légales] qui leur incombaient. [Concernant] ces états spirituels, - qui sont accompagnés de la perte de connaissance, de la mort, de la folie, de l'ivresse ou bien de l'extinction jusqu'au point où [l'extatique] n'a plus conscience de lui-même - si les causes en sont licites, et si celui qui [traverse cet état] est sincère dans son incapacité à repousser ce qui lui survient, celui-ci est alors agréé pour le bien qu'il a accompli et pour la foi qu'il a obtenue. De même qu'il est excusable [en ce qui concerne son état], du fait de son incapacité à repousser ce qui survient contre son gré. Celui-ci est en tout point meilleur que ceux qui n'ont pas atteint son degré (manzila), à cause de leur manque de foi, de la dureté de leurs cœurs, et à cause de motifs similaires qui les poussent à abandonner ce que Dieu aime et à faire ce que Dieu déteste.

Cependant, à [ceux qui sont ravis], on préférera celui dont l'entendement n'est pas annihilé, et ce, quel que soit le degré de foi qu'il ait reçu, identique ou bien supérieur à [ceux qui sont ravis]. Ainsi fut l'état spirituel des Compagnons ${ }^{(\mathrm{QDA}) 143}$ et de notre Prophète (PSDL)144. En effet, celui-ci fut élevé aux Cieux, où Dieu lui révéla ce qu'Il lui révéla ${ }^{145}$, puis il se réveilla comme s'il n'avait pas quitté [sa demeure] ; en effet son état ne s'était point altéré.

C'est pourquoi son «état spirituel » est supérieur à celui de Moïse ${ }^{(\mathrm{PSDL}) 146}$ qui « tomba foudroyé » lorsque "Dieu se manifesta sur le Mont ${ }^{147}$ ». L'état spirituel de Moïse est [certes] vénérable (ğalìla), élevé ('āliyya) et méritoire (fädilia), cependant l'état spirituel de Muhammad ${ }^{(\mathrm{PSDL})}$ est plus ${ }_{[13]}$ complet (akmal), plus élevé (a'lā) et plus méritoire (afḍal).

Ce qu'il faut retenir, c'est que ces phénomènes de zèle dans la dévotion et d'exagération dans les états spirituels viennent de Bassora. La cause ${ }^{148}$ en est une peur intense [de Dieu] (šiddat al-h̆awf). Ce qui a été mentionné à propos de la peur de 'Utbat al-Ġulām, de 'Ațāa' al-

141. Homerin a traduit mağnūn par possessed, voir HomeRIN 1985, p. 228.

142. À propos de ces «fous de Dieu » et du prestige dont ils jouissaient au sein de la cité, notamment à l'époque d'Ibn Taymiyya, voir Geoffroy 1995a, p. 309-333 ; GriL 2006, p. 58.

143. Pour la suite du texte l'abréviation QDA pour « Que Dieu les agrée » ou « Que Dieu l'agrée ».

144. PSDL pour « Prière et salut de Dieu sur lui ».

145. Référence au « Voyage nocturne » du Prophète, mentionné dans Coran 53 : 1-18.

146. En règle générale, cette formule n'est employée que pour le Prophète. Nous avons opté pour le nom francisé « Moïse » plutôt que Mūsā.

147. Voir Coran 7 : 143. Les expressions « tomba foudroyé » et « Dieu se manifesta sur le Mont » proviennent de la traduction de D. Masson.

148. Selon Kalābādī, «les états qui exercent plus ou moins leur emprise peuvent être la peur, la crainte révérencielle, la vénération profonde, ou la honte ». Voir KaLĀBĀD̄ī, Traité de soufisme, p. 126. 
Sulaymī ${ }^{149}$ et des autres, est assurément une affaire remarquable. Il n'y a aucun doute sur le fait que leur état spirituel est plus parfait et plus méritoire que [l'état] de celui qui ne les a ni égalés, ni dépassés [en mérite] dans la crainte de Dieu. Cependant, est plus méritoire l'état spirituel de celui qui craint Dieu de manière modérée (muqtașidan) ; crainte l'invitant à faire ce que Dieu aime et à délaisser ce qu'Il déteste et ce sans s'adonner aux excès [mentionnés ci-dessus]. Ce fut l'état spirituel des Compagnons ${ }^{(\mathrm{QDA})}$. Il est relaté qu'après la mort de 'Ațā' al-Sulaymī (QDA), quelqu'un le vit en rêve et lui demanda ce que Dieu avait fait de lui. Il répondit : Dieu m'a interpellé et m’a dit : «Oh, 'Ațā', n'as-tu pas honte de me craindre à un tel degré ? Ne t'est-il pas parvenu que je suis le Tout Recouvreur [des fautes] (g்aūr ${ }^{150}$ et le Miséricordieux (rahīm) ?». Et ainsi, on a mentionné d'autres, semblables aux [gens de Bassora] qui, dans leurs états spirituels (ahwwāl), le renoncement (zuhd), l'abstention scrupuleuse (wara'), la dévotion ('ibāda) et bien d'autres choses, furent plus zélés que les Compagnons ${ }^{(\mathrm{QDA})}$ et [allèrent au delà de] ce qu'avait prescrit le Messager. Ce qui a eu pour conséquence la division des gens en deux groupes : un groupe condamnant et dénigrant [les extatiques]. [Ce groupe] est sans doute allé trop loin dans sa condamnation. ${ }_{[14]}$ Un [autre] groupe a exagéré à leur propos, et a considéré leur voie comme la plus parfaite et la plus élevée des voies.

La vérité, c'est que dans ces dévotions et les états spirituels [qui en résultaient], [les gens de Bassora] faisaient preuve d'une application personnelle (muğtahidūn) ${ }^{151}$, tout comme leurs voisins de Coufa, qui s'appliquaient sur les questions de justice (qad $\left.\bar{a}^{\prime}\right)$, de pouvoir (imāra), etc. Puis, émergea parmi [les gens de Coufa], [le principe] de l'opinion personnelle (ra'y) ${ }^{152}$, qui était, en certains points, contraire à la Sunna et que la majorité des gens ont désapprouvé.

L'élite parmi les gens du figh et de l'opinion (ra'y), ont [de la même manière] divergé à propos des [gens de Coufa qui ont émis une opinion erronée] et ainsi deux groupes se formèrent : un groupe qui les condamnait de manière exagérée et [à l'inverse] un groupe qui les louait et les glorifiait à l'excès, en les considérant comme les plus grands savants en matière de fiqh. Et peut-être même les préféraient-ils aux Compagnons, à l'instar des [exagérateurs] qui louaient les dévots [de Bassora] et qui, sans doute, les préféraient aux Compagnons. C'est un domaine à propos duquel les gens se sont divisés (yaftariqu).

En réalité, le musulman doit savoir que la meilleure des paroles est celle de Dieu, la meilleure des guidances, celle de Muhammad (PSDL), la meilleure époque, celle à laquelle il fut envoyé [aux Compagnons] ${ }^{153}$, la meilleure des voies et des chemins vers Dieu, celle que suivirent [le Prophète] et ses compagnons. De ce qui précède, nous savons que les croyants doivent craindre Dieu selon leur capacité (wus') et leur degré d'application (iğtihād), ainsi que Dieu l'a dit: \{Craignez Dieu autant que vous le pouvez. [...]\} (Coran $64: 16)$. Le

149. À propos de ces deux personnages voir Homerin 1985, p. 229, n. 37.

150. GLOTON 2007, p. 95.

151. Pour la traduction de muğtahidūn, HoMERIN a opté pour l'expression suivante : «ils formulaient leurs propres opinions ». Voir HOMERIN 1985, p. 229.

152. Pour les débuts de la méthodologie juridique, voir URVOY 2006, p. 125-143.

153. Musum, Șahīḥ, $44: 52: 213$ (kitāb faḍảil al-șaḥāba). 
[Prophète] a dit ${ }^{\text {(PSDL) }}:_{[15]}$ "Si je vous ordonne quelque chose, accomplissez-le selon ce dont vous êtes capables ${ }^{154} »$. Dieu à dit: \{Dieu n'impose à chaque homme que ce qu'il peut porter. [...]\} (Coran $2: 286$ ).

Ainsi, de nombreux croyants, - des pieux qui sont des « Amis de Dieu » (awliyā) 155 - à qui n'est pas parvenue la perfection du savoir et de la foi qui était parvenue aux Compagnons, craignaient Dieu dans la mesure de leur capacité et Lui obéissaient selon leur degré d'application. Par conséquent, il est inconcevable qu'ils soient exempts d'erreurs dans leurs savoirs ${ }^{156}$, leurs doctrines (aqwāl), leurs actes ou bien concernant leurs états spirituels. Ils seront récompensés dans la mesure de leur obéissance [à Dieu] et pardonnés pour leurs erreurs, comme Dieu le Très-Haut l'a dit : \{Le Prophète a cru à ce qui est descendu sur lui de la part de son Seigneur. Lui et les croyants ; tous ont cru en Dieu, en ses anges, en ses Livres et en ses prophètes. Nous ne faisons pas de différence entre ses prophètes. Ils ont dit: «Nous avons entendu et nous avons obéi ». Ton pardon notre Seigneur ! Vers toi est le retour final!\}[..] \{Notre Seigneur! Ne nous punis pas pour des fautes commises par oubli ou par erreur [...]». (Coran $2: 285-286$ ). [Dans un hadith rapporté par Muslim], Dieu le Très-Haut a dit : «Et j'ai [pardonné] » ${ }^{157}$.

Par conséquent, celui qui considère la voie des savants ou des juristes [de Coufa] ou bien des dévots ('ubbād) ou des renonçants (zuhhād) [de Bassora], supérieure à celle des Compagnons, il est dans l'erreur et dans l'égarement et c'est un innovateur (mubtadi'). Quant à celui qui condamne, et qui désigne comme fautifs (ma'î̉) et haïssables (mamqūt) ceux qui, tout en s'appliquant dans la voie de l'obéissance, commettent des erreurs, celuici est [lui-même] dans l'erreur et dans l'égarement et c'est un innovateur (mubtadi').

De même, dans l'amour, la haine, l'amitié et l'animosité, les gens émettent des jugements et il arrive que, parfois, ils soient dans le vrai et parfois dans le faux. En effet, beaucoup de gens, s'ils aiment quelque chose chez un homme, alors ils lui portent un amour absolu, au point de s'aveugler sur ses défauts. Ou bien, s'ils détestent quelque chose chez un homme, alors ils lui portent une haine absolue, au point de s'aveugler sur ses qualités. [.... ${ }^{158}{ }^{116]}{ }_{[16}$ Une doctrine [aussi excessive] provient des innovateurs, des kharidjites, des mutazilites, et des murdjites.

Selon les ahl al-sunna wa al-ğamāa le Coran, la Sunna et le consensus [des oulémas] indiquent que le croyant mérite (yastahiqqu) la promesse de Dieu et sa grâce : c'est-à-dire la récompense pour ses bonnes actions et le châtiment pour ses mauvaises actions. En effet,

154. BUHĀR̄ì, Șaḥihh, $96: 2: 7288$ (kitāb al-ítișām).

155. Le terme de wali faisant référence à la proximité, nous avons opté pour «Ami » au lieu de «Saint ». D’autre part, voir les avertissements de J-C. Garcin à propos de l'emploi du terme « Saint » : GARCIN 2006, p. 33-34.

156. Cette précision vise implicitement les doctrines qui affirmeraient l'infaillibilité du wal̄, et par extension sa suprématie sur le nabì. Pour Ibn Taymiyya, seuls les prophètes sont infaillibles (ma șūm). De ce fait, l'infaillibilité ne peut s'étendre aux Compagnons - les meilleurs de la création après le Prophète - et encore moins aux imâms chiites et aux «Saints ». En revanche, le savant hanbalite estime le consensus des Salaf comme infaillible. Voir Ibn Taymiyya, La profession de foi d'Ibn Tamiyya, p. 81 ; Laoust 1939, p. 239. Sur le rapport prophétie/sainteté et sur la doctrine de l'infaillibilité, voir supra, n. 62.

157. Musuim, Șaḥīh, $1: 57: 200$ (kitāb al-īmān).

158. L'éditeur signale plusieurs incohérences qui rendent le texte incompréhensible. Voir la remarque de HomERIN 1985, p. 231, n. 39. 
une même personne rassemble en elle aussi bien ce qui est digne de récompense que ce qui mérite le châtiment ; ce qui est louable et ce qui est blâmable ; ce qui est appréciable et ce qui est détestable. Ainsi en est-il.

Il est donc connu que le tașawwuf est originaire (manša') de Bassora. Et il y avait dans cette ville ceux qui suivaient la voie de la dévotion ('ibāda) et du renoncement (zuhd), en s'y appliquant à leur manière (iğtihād). Tout comme il y avait à Coufa, ceux qui suivaient la voie de la jurisprudence (figh) et de la science [religieuse] ('ilm), en s'y appliquant (iğtihād) [également] à leur manière.

Cependant, les premiers ont été identifiés à une apparence vestimentaire : le vêtement de laine. Ainsi, ils furent nommés șüfï. Néanmoins, leur voie ne se limite pas au port d'un vêtement de laine, d'autant que celui-ci n'est ni une exigence de leur part, ni une des conditions de leur voie. Cette dénomination leur a été attribuée à cause de leur apparence (zāhir al-hāl).

Selon [les soufis], le tașawwufrenferme des « réalités métaphysiques » (haqāiq ${ }^{159}$ et des états spirituels ( $($ h $w$ āll) bien connus. Les définitions du soufisme, ses mœurs ( $a h l a ̄ q)$ ainsi que la manière (sìra) [de cheminer sur la voie], ont été abordées par les [auteurs soufis]. Ainsi, il est dit que le șūfi est celui qui est pur de tout ce qui est trouble (kadar), qui est empli de méditation, et pour qui l'or et la pierre se valent ${ }^{160}$. [Il est dit par ailleurs] que le tașawwuf, c'est la dissimulation des sens spirituels (kitmān al-ma'ānī) et l'abandon des prétentions (tark al-da'ā $w \bar{\imath})^{161}$. Il existe d'autres définitions de la sorte. Ils ont par ailleurs identifié le soufi ${ }_{[17]}$ au véridique (șiddīq) ${ }^{162}$. [Sachant que] les meilleurs des hommes, après les prophètes, sont les véridiques (șiddīqūn). Ainsi que Dieu l'a dit : \{Ceux que Dieu a comblés de bienfaits ; avec les prophètes, les véridiques (șiddīqīn), les témoins (šuhadā') et les vertueux (șâlihịin): voilà une belle assemblée ! \} ${ }^{163}$ (Coran $4: 69$ ). C'est pourquoi, ils ${ }^{164}$ estiment qu'après les prophètes, les plus méritants sont les soufis. En vérité, le soufi n'est qu'un véridique parmi d'autres classes (naw') de véridiques ; c'est celui qui s'est distingué par le renoncement et la dévotion, selon une manière qui lui est propre et dans laquelle il s'applique. De ce fait, le véridique fait partie de cette voie [soufie]. De même qu'il est mentionné des véridiques parmi les oulémas et des véridiques parmi les dirigeants (umarā'). Cependant, [le soufi] est meilleur (ahașs) que le véridique absolu (al-șiddìq al-muțlaq), sans pour autant dépasser le degré du véridique parfait (al-șiddīq al-kāmil) qui fut celui des Compagnons, des Suivants et de leurs successeurs [immédiats].

159. Une autre traduction pourrait être : « vérités spirituelles ».

160. Définition attribuée à Sahl al-Tustarī (m. 896), citée dans KALĀBĀD̄Ī, Traité de soufisme, p. 30.

161. Le soufi Ǧafar al-Hुaladī (m. 959) dit avoir questionné, en rêve, le Prophète sur ce qu'est le tașawwuf; celuici lui aurait répondu: "tark al-da'āwì wa kitmān al-ma'ānī». La chaîne de transmission débute avec Ibn al-Ǧawzī (m. 1200) et se termine avec 'Alī b. Ǧa far al-Ḥanbalī al-Ǧamāl. Voir IBN AL-NAĞĞĀR, Dayl tārīh Baḡdād, vol. III, p. $242-243$.

162. La plus ancienne mention de ce terme remonterait à 'Abd al-Wāḥid b. Zayd (m. 793). Voir MAssiGnon 1999, p. 215.

163. D. Masson a traduit les termes șiddīqin et șālihìn, par les « justes » et les « saints ». Concernant notre choix de traduction voir supra, n. 61.

164. C'est-à-dire, les soufis eux-mêmes. 
Par conséquent, dire que les renonçants et les dévots de Bassora sont des véridiques équivaut à ce qui est dit à propos des juristes de Coufa : ce sont également des véridiques ; chacun selon leur application dans la voie de l'obéissance à Dieu et à son envoyé. De par leur époque ${ }^{165}$, ils furent parmi les plus illustres véridiques. En revanche le véridique de la première période [de l'islam] fut plus parfait qu'eux.

Il y a différents degrés et types de véridiques, c'est pourquoi il existe pour chacun d'entre eux des états spirituels et des pratiques dévotionnelles spécifiques que [le cheminant, tour à tour] réalise (haqqaqa), parachève à la perfection (ahkama), [puis] dépasse (ġalaba 'alā). Néanmoins, il peut exister d'autres que celui-ci, issus de catégories différentes, plus parfaits et plus méritant que lui.

À cause de leur ${ }^{166}$ application personnelle (iğtiḥ̄ad) et des divergences qui en découlèrent (tanāzu' fì-hi), les gens se sont disputés (tanāza'a) à propos de la voie [soufie]. Un groupe a condamné les soufis et le soufisme, en affirmant qu'il s'agissait ${ }_{[18]}$ d'innovateurs et qu'ils étaient en dehors de la sunna. Une telle condamnation, dont les propos restent célèbres, est mentionnée à propos d'un groupe d'imams. Ils ont été suivis [dans leur condamnation] par les gens du figh et du kalām. Un [autre] groupe a exagéré à propos [des soufis], prétendant qu'ils étaient les plus méritants (afdal) et les plus parfaits (akmal) après les prophètes. [En réalité], ces deux positions extrêmes sont condamnables.

La vérité, c'est que [les soufis] s'appliquent dans l'obéissance à Dieu, tout comme d'autres s'y sont appliqués. C'est pourquoi il y a parmi [les soufis], le rapproché de Dieu (al-sābiq almuqarrab) de par son application et le modéré (muqtașad) qui fait partie des gens de la droite (ahl al-yamin $)^{167}$. Dans chacune de ces deux catégories, il y a celui qui, tout en s'appliquant [dans sa voie], s'est trompé ; ou bien un autre a péché, puis s'est repenti ou ne l'a pas fait ${ }^{168}$.

Parmi ceux qui se réclament [des soufis], il y a [également] l'injuste (zālim li-nafsi-hi) qui est rebelle envers son Seigneur. En effet, des innovateurs et des hérétiques (ahl al-zandaqa) se sont réclamés des soufis. Cependant, les soufis authentiques (al-muhaqqaqin min ahli-ltașawwuf) ne les considérèrent pas comme des leurs. À l'exemple de Hallāğ, que les maîtres [du soufisme], tels Ǧunayd le «Prince de l'Ordre » et d'autres, ont désavoué et exclu de la voie ; ainsi qu'il est rapporté par le šayh̆ Abū 'Abd al-Raḥmān al-Sulamī dans ses Ṭabaqāt alșūfiyya, et par al-Hāfiz Abū Bakr al-Ḩațīb dans son Tārīh Bag̉dād.

Voilà ce que fut le soufisme originel (așl), mais ce n'est qu'après qu'il s'est divisé en plusieurs branches et espèces (taša aba wa tanawwa'a), donnant lieu à ${ }_{[19]}$ trois catégories (așnāf) de soufis: ceux des «réalités métaphysiques" (șūfiyyat al-ḥaqāiq), les soufis

165. Il faut comprendre : de par la proximité de leur époque avec celle du Prophète et des Compagnons.

166. C'est-à-dire, l'iğtihād des soufis et les divergences qui découlent de leurs efforts personnels.

167. Cette terminologie figure dans les versets 7 à 11 de la sourate al-Wāqi'a (n56). Voir nos remarques à propos de l'exégèse de ces versets, supra, p. 118-119.

168. Il s'agit d'une nouvelle référence implicite à l'infaillibilité réservée aux seuls prophètes. Voir nos remarques supra, n. 156. 
« financés » ${ }^{169}$ (șūfiyyat al-arzāq) et ceux des «apparences» (șūfiyyat al-rasm). Les șūfiyyat al-haqā’iq sont ceux que nous avons décrits précédemment ${ }^{170}$.

Quant aux șūfiyyat al-arzāq, ce sont ceux-là qui ont bénéficié des fruits des « fondations pieuses » (waqf, pl. wuqūf ou awqāf), tels, les hānqāh ${ }^{171}$. Cependant, ils ne font pas nécessairement partie des « soufis des réalités métaphysiques ». Car ces derniers sont rares et la majorité d'entre eux ne se caractérise pas par un besoin de [fréquenter] les ḩānqāh ${ }^{172}$. Cependant, ils doivent [se conformer] à trois conditions : la première, c'est le respect de la loi divine (šarîa), c'est-à-dire accomplir les devoirs religieux (farāid et éviter les interdits (mahārim). La seconde condition, c'est le respect des règles de bienséance (ādāb) de la Voie ${ }^{173}$, qui ne sont, la plupart du temps, que celles de la šaría. Nous ne nous arrêterons pas ici sur les coutumes hérétiques (al-ādāb al-bid'iyya) et les convenances instituées (al$\bar{a} d \bar{a} b$ al-wad'iyya) [par les hommes]. [Et enfin], la dernière des conditions, c'est qu'ils ne soient pas attachés aux biens de ce monde. Cependant, celui qui amasse les biens, ou qui n'a pas acquis les bonnes mœurs, ou qui ne se conforme pas aux principes de la šarî́a, ou bien encore se livre à la débauche, celui-ci ne mérite pas [le rang, dont il est question ici].

Quant aux "soufis des apparences ", ils n'ont de soufi que le titre. Ils donnent de l'importance aux habits ${ }_{[20]}$, aux convenances instituées [par les hommes], etc. Leur [soufisme] se limite à l'apparence vestimentaire des savants et des « combattants dans la voie de Dieu ». Leurs paroles et leurs actions ne sont que d'emprunt; au point où l'ignorant les confondrait avec les [soufis authentiques], alors qu'il n'en est rien.

Quant au terme "pauvre» (faqīr), il figure dans le Livre de Dieu et les propos de son prophète ${ }^{(\mathrm{PSDL}) 174}$. Et, dans les deux cas, ce qui est visé par le terme faqìr, c'est le

169. D'après le texte, nous comprenons qu'il s'agit du soufisme confrérique «financé » par les «fruits des fondations pieuses ». À ce propos, Louis Pouzet signale que la majorité des confréries soufies de Damas étaient institutionnalisées et regroupées en syndicat; elles entretenaient de bons rapports avec le pouvoir, qui pouvait parfois se montrer généreux donateur, à l'exemple des dix mille pièces d'argent que Kitbug̣ā offrit aux Qalandariyya. Voir Pouzet 1991, p. 228 ; GARCin 2006, p. 22. À propos des șūfiyyat al-arzāq, E. Geoffroy (2010, p. 71) écrit : « Les résidents des ḩānqāh étaient, paraît-il, si prospères que le voyageur Ibn Ğubayr, visitant Damas au xII siècle, voyait en eux "les rois de ce pays". Beaucoup de maîtres soufis "privés" qui investissaient, eux, les zāwiya, se sont montrés réticents face à cette institutionnalisation du soufisme, et critiquaient les personnes résidant dans les hānqāh. Ces personnes percevaient en effet une sorte de salaire, alors que les «pauvres en Dieu », les soufis en général, sont censés s'en remettre à la providence divine, ou encore gagner leur vie ». Michot (2007, p. 24) traduit șüfiyyat al-arzāq par « soufis stipendiés ». Néanmoins, nous pensons que le terme «stipendié » a une connotation péjorative qui ne permet pas d'exprimer pleinement l'opinion du šayh̆ al-istām. En effet, rien dans la suite du texte ne laisse présager une telle option. Ibn Taymiyya ne semble pas s'opposer au financement des confréries mais affirme que celui qui amasse les biens ne peut prétendre être un soufi.

170. C'est-à-dire ceux qui vivent, assimilent et maîtrisent les états spirituels et les formes de dévotion.

171. Hāānqāh ou hā̄nkāh (pl. hawānik), terme persan désignant le « couvent soufi ». Pour une différence entre hānqāh et zāwiya, voir GEOFFroy 1995a, p. 166-175.

172. Homerin signale une divergence dans l'édition de Rašīd Riḍā, voir HoMERIN 1985, p. 233, n. 45.

173. Sur l'importance des règles de bienséance de la Voie, voir GriL 1996b, p. 96.

174. Cette autre «digression » est très probablement une référence à un débat de l'époque, que nous n'avons cependant pas pu identifier. 
contraire du « riche ». Ainsi que le Prophète ${ }^{(\mathrm{PSDL})}$ l'a dit ${ }^{175}$. Les pauvres et la pauvreté sont de plusieurs sortes, y compris [la pauvreté] qui est éligible à la perception de l'aumône légale (zakāt). À cela s'oppose la richesse, qui interdit de percevoir la zakāt. Ainsi que le Prophète ${ }^{(\mathrm{PSD})}$ l'a dit : «Il n'est permis ni au riche, ni à celui qui a les capacités de gagner sa vie, de percevoir la charité». Quant au [seuil de] richesse impliquant le payement de la zakāt, selon la majorité des oulémas, cela se distingue du [cas évoqué par le Prophète]. C'est l'opinion de Mālik [b. Anas], de Šâfi'î et d'Ahmad [b. Hanbal]. Selon eux, [le seuil] impliquant le payement de la zakāt est défini par la possession du quota minimum (nișāb). Il peut [donc] être autorisé à une personne imposable à la zakāt de percevoir la zakāt. Abū Hanīfa ne partageant pas cet avis. Dieu, gloire à Lui, a mentionné les pauvres dans [différents versets du Coran]. Ceux éligibles à percevoir l'aumône légale sont mentionnés dans un verset et ceux ayant droit au butin, dans un autre. Dans un premier [groupe de versets], il a dit: \{Si vous donnez vos aumônes d'une façon apparente, c'est bien. Si vous le cachez pour les donner aux pauvres, c'est préférable pour vous. [...] Quant aux aumônes que vous donnez aux pauvres qui ont été réduits à la misère dans le chemin de Dieu $_{[21]}$ et qui ne peuvent plus parcourir la terre; - L'ignorant les croit riches, à cause de leur attitude réservée. Tu les reconnais à leur aspect : ils ne demandent pas l'aumône avec importunité -\} (Coran 2 :271-273). Dans un second [groupe de versets], il a dit: \{Ce que Dieu a octroyé à son Prophète comme butin pris sur les habitants des cités [...]. Le butin est destiné aux émigrés qui sont pauvres, qui ont été expulsés de leurs maisons et privés de leur bien tandis qu'ils recherchaient une faveur de Dieu et sa satisfaction et qu'ils portaient secours à Dieu et à son Prophète ; - ceux-là sont les véridiques! - $\}$ (Coran $59: 7-8$ ).

Et il se peut qu'il y ait parmi ces pauvres un qui soit de loin plus méritant (afdal) que les riches. [De même] qu'il se peut qu'il y ait parmi les riches un qui soit beaucoup plus méritant que [ces pauvres]. Les gens se sont disputés, s'agissant de savoir qui, du pauvre patient, ou du riche reconnaissant, était le plus méritant ${ }^{176}$. En vérité, le meilleur d'entre eux est le plus pieux. S'ils ont le même degré de piété, alors ils auront le même rang [au paradis], ainsi que nous l'avons illustré par ailleurs. Ainsi, les pauvres précéderont les riches au paradis, parce qu'ils n'ont pas de comptes à rendre. Puis ce sera [au tour] des riches de rendre compte. Celui dont les bonnes actions pèsent plus lourd que celles du pauvre, son rang au paradis sera plus élevé ; même s'il ne rentre qu'après lui. Quant au riche dont les bonnes actions sont moindres que celles du pauvre, son degré au paradis en sera moins élevé.

Du fait que le renoncement (zuhd) était plus répandu chez les pauvres, beaucoup assimilèrent le faqr à la voie du renoncement (zuhd), qui relève du genre soufisme. Le fait

175. L'éditeur signale qu'il en est ainsi dans le manuscrit. Nous estimons que les propos qui suivent ne sont pas ceux du Prophète, mais d'Ibn Taymiyya. En effet, ceux-ci ne se trouvent dans aucun des corpus de hadiths habituellement cités par le savant hanbalite. Homerin pense qu'il s'agit d'un dit du Prophète, tout en signalant qu'il ne figure pas dans les principaux corpus de hadiths. Voir Homerin 1985, p. 234, n. 46.

176. Ibn Taymiyya a consacré plusieurs fatwa à ce sujet, voir IBN TAYMIYYA, Mağmū' al-fatāwā, vol. XI, p. 119-121, 122133 et 195. Ce débat est également relaté dans MAкKī, Qūt al-qulūb, vol. 1, p. 264. 
de dire qu'un tel est « pauvre » ou ne l'est pas, ne se rapporte pas à la pauvreté matérielle ; mais se rapporte à la signification du terme soufi, c'est-à-dire : les connaissances (ma'ärif), les états spirituels ( $(a h w \bar{a} l)$, les bonnes mœurs $(a h l a \bar{q})$ ), les règles de bienséance (ādāb), etc.

À ce propos, il y eut divergence, à savoir qui du faqiir ou du soufi avait le plus de mérite? Il y eut un groupe qui préféra le soufi, tel Abū Ğa far al-Suhrawardī ${ }^{177}$ et d'autres. Alors que de nombreux groupes ont opté pour le faqìr. Peut-être ${ }_{[22]}$ se distinguaient-ils par le fait que les [premiers] fréquentaient les zāwiya, tandis que les faqīr [fréquentaient] les hāanqāh ${ }^{178}$. $\mathrm{Ou}$, quelque chose comme cela. Cependant, la majorité des gens préféraient le faqiir.

La vérité, c'est que le plus méritant d'entre eux est le plus pieux. Si le soufi craint Dieu, alors il est meilleur dans la mesure où il pratique ce qui est aimé de Dieu et s'éloigne de ce qui est détesté de Lui. Et [dans le cas inverse], c'est le faqìr qui est meilleur. Par conséquent, s'ils s'égalent dans l'action aimée [de Dieu] et dans l'abandon de ce qui est détesté [de Dieu], alors ils ont le même rang [au paradis].

Les «Amis de Dieu » (awliy $\bar{a}$, sing. wali $)$ sont les croyants pieux, qu'importe [leurs titres], qu' ils soient faqīr, soufis, faqïh, savants, commerçants, combattants, artisans, princes, gouverneurs ou autre chose. Ainsi que Dieu, le Très-Haut, l'a dit : \{Non, vraiment, les amis de Dieu n'éprouveront plus aucune crainte, ils ne seront pas affligés ; - ceux qui croient en Dieu et qui le craignent -$\}$ (Coran $10: 62-63$ ).

Un hadith [qudsī], figurant dans le Șahịḥ de Buhārī, rapporté par Abū Hurayra ${ }^{179}$ à propos du Prophète ${ }^{(\mathrm{PSDL})}$ qui a dit: «Dieu a dit: Quiconque montre de l'hostilité à un de «Mes Amis» (walī), Je lui déclare la guerre. Mon serviteur ne s'approche de Moi que par ce que J'aime le plus, par les devoirs religieux que Je lui ai prescrits, puis mon serviteur ne cesse de se rapprocher de Moi par des œuvres surérogatoires (nawāfil) jusqu'à ce que Je l'aime. Quand Je l'aime, Je suis son ouïe par laquelle il entend, sa vue par laquelle il voit, sa main par laquelle il saisit et son pied avec lequel il marche. C'est donc par Moi qu'il entend, qu'il voit, qu'il saisit, et qu'il marche. Qu'il Me demande [quelque chose], et Je [le] lui donnerai sûrement, et qu'il Me demande refuge, Je le lui accorderai sûrement. Aucune chose ne Me fait hésiter ${ }^{180}$ plus que [de prendre] l'âme de Mon fidèle serviteur ; il déteste la mort et Je déteste lui faire du mal. Mais cela est inévitable ». Ce hadith illustre parfaitement ${ }_{[23]}$ ce que sont les « Amis modérés de Dieu » (awliyā" Allāh al-muqtașidīn) : ce sont les compagnons de la droite et les rapprochés [de Dieu], les devanciers. La première

177. Abū Ğa far al-Suhrawardī (m. 1191), le šayh al-išrāq. À son propos voir CoRBIN 1986, p. 285-305. Cependant, Homerin (1985, p. 235, n. 51) signale que dans l'édition Rašīd Riḍā, à la place d'Abū Ǧa'far, figure (à juste titre) le nom du soufi bagdadien Šihāb al-Dīn Abū Hafș 'Umar al-Suhrawardī (m. 1234), l'auteur des 'Awārif al-ma'ārif. Cette dernière option nous semble plus plausible, d'autant que Pouzet (1991, p. 209) signale qu'Abū Hafș, un des relais de l'enseignement du šayh̆ 'Abd al-Qādir al-Ğīlānī (m. 1166), marqua profondément les milieux soufis de la capitale syrienne.

178. Ibn Taymiyya ne présente pas clairement la nuance entre soufis et fuqarā', hormis la distinction relative aux lieux qu'ils fréquentent : zāwiya ou hānqāh. Laoust (1939, p. 22) note que les fuqarā' sont des ascètes ayant fait «vœu de renoncement aux biens de ce monde ». Concernant zāwiya, hānqā et ribāt à l'époque mamelouke, voir GARCIN 2006, p. 17-26; GEOFFroy 1995a, p. 166-175.

179. À propos de l'usage de ce hadith, voir supra, n. 65.

180. Sur le thème de l'hésitation de Dieu, dans le cadre de ce hadith, voir textes d'Ibn Taymiyya dans Michot 2004. 
catégorie [les compagnons de la droite] désigne ceux qui se rapprochent de Dieu par les actes obligatoires. Tandis que la deuxième [catégorie] se rapporte à ceux qui se rapprochent de Dieu par les actes obligatoires suivis des actes surérogatoires. Et ce sont ceux-là qui ne cessent de se rapprocher de lui, jusqu'à ce qu'Il les aime. Ainsi que le Très-Haut l'a dit [dans ce hadith qudsi] ${ }^{181}$.

Dieu a par ailleurs mentionné ces deux catégories dans le Coran [en ces termes]: \{Nous avons ensuite donné le Livre en héritage à ceux de nos serviteurs que nous avons choisis : il en est parmi eux qui se font tort à eux-mêmes; il en est parmi eux qui se tiennent sur une voie moyenne; il en est parmi eux qui, avec la permission de Dieu, devancent les autres par leurs bonnes actions [...]\} (Coran $35: 32$ ). \{Oui, les purs vivront dans les délices ; étendus sur des lits d'apparat, ils regarderont autour d'eux. Tu verras sur leurs visages l'éclat de la félicité. On leur donnera à boire un vin rare, cacheté par un cachet de musc - ceux qui en désirent peuvent le convoiter - et mélanger à l'eau du Tasnim, une eau qui est bue par ceux qui sont proches de Dieu.\} (Coran 83 : 22-28).

[À ce propos], Ibn 'Abbās a dit : « Les rapprochés [de Dieu] boiront [un vin] pur, tandis qu'il a été mélangé pour les compagnons de la droite ».

Le Très-Haut a dit : \{lls boiront une coupe dont le mélange sera de gingembre, puisé à une source nommée là-bas: «Salsabil»\} (Coran 76:17-18). \{Les compagnons de la droite ! - Quels sont donc les compagnons de la droite ? - Les compagnons de la gauche ! - Quels sont donc les compagnons de la gauche? - Et les premiers arrivés ${ }^{182}$ qui seront bien les premiers, voilà ceux qui seront les plus proches de Dieu.\} (Coran $56: 8-11$ ). \{ $\mathrm{Si}$ cet homme est au nombre de ceux qui sont proches de Dieu, il trouvera le repos, les parfums et les Jardins du Délice. S'il est au nombre des compagnons de la droite : « Paix à toi !... Tu es avec les compagnons de la droite ».\} (Coran $56: 88-91$ ).

Cette réponse contient des propos nécessitant de longues explications, qui ne peuvent se faire ici. Et Dieu est le plus Savant.

181. Sur le débat concernant le qurba al-nawāfil et le qurb al-farāid, entre Ibn Taymiyya et l'école d'Ibn 'Arabī, voir CHODKIEWICZ 1984a, p. 189-200.

182. Sur la traduction du terme sābiqūn, voir nos remarques supra, n. 70. 


\section{RÉFÉRENCES}

ABū Nu' Aym AL-IșBahĀNī̄, Aḥmad ibn 'Abd Allāh, 1988 : Ḥilyat al-awliyā’ wa-țabaqāt al-așfiyā', Beyrouth, Dār al-kutub al-ilmiyya.

AIGLE, Denise, 2007 : «The Mongols invasions of Bilād al-Shām by Ġāzān Hูān and Ibn Taymiyya's three « anti-mongol » fatwas », Mamluk Studies Review 11/2, p. 89-120.

AigLE, Denise, 2011 : «Essai sur les autorités religieuses dans l'islam médiéval oriental », dans D. AigLE (dir.), les autorités religieuse entre charisme et hiérarchie. Approches comparatives, Turnhout, Brepols, p. 17-40.

Amitai-Preiss, Reuven, 1995 : Mongols and Mamluks, Cambridge, Cambridge University Press.

Anș̄īĩ, 'Abd Allāh ibn Muhammad Abū Ismāî̀l, Chemin de Dieu : trois traités spirituels, Trad. par S. de Beaurecueil. Arles, Sindbad, 1997.

BöWERING, Gerhard, 1996 : « The Major Sources of Sulamî’s Minor Qur'ān Commentary », Oriens 35, p. 35-56.

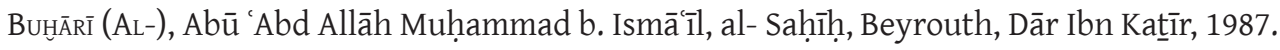

Снавві, Jacqueline, 1977 : «Remarques sur le développement historique des mouvements ascétiques et mystiques au Khurasan : III $/ \mathrm{IX}^{\mathrm{e}}$ siècle - IV $/ \mathrm{x}^{\mathrm{e}}$ siècle ", Studia Islamica 46, p. 5-72.

Cноркіеwicz, Cyrille, 1984a: Les premières polémiques autour d'Ibn 'Arabī : Ibn Taymiyya (661-728/1263-1328), thèse de $3^{e}$ cycle, Paris, Université Paris IV.

CHodkiewicz, Michel, 1984b : «Le procès posthume d'Ibn 'Arabī », F. De Jong and B. RADTKE (dir.), Islamic Mysticism Contested: Thirteen Centuries of Controversies and Polemics, Leiden, Brill, p. 93-123.

Сноркіеwicz, Michel, 1984c: Le Sceau des saints : prophétie et sainteté dans la doctrine d'Ibn Arabî, Paris, Gallimard.

CORBIN, Henry, 1986 : Histoire de la philosophie islamique, Paris, Gallimard.

GARCIN, Jean-Claude, 1995 : « Le Proche-Orient à l'époque mamluke », dans J.-Cl. GARCIN (dir.), États, sociétés et cultures du monde musulman médiéval $X^{e}-x^{e}$ siècles, Paris, PUF, vol. 1, p. 343-369.

GARCIN, Jean-Claude, 2006 : «Les soufis dans la ville mamelouke d'Égypte. Histoire du soufisme et histoire globale », dans R. McGRegor et A. SABRA (dir.), Le développement du soufisme en Égypte à l'époque mamelouke, Le Caire, IFAO, p. 11-39.

GARDET, Louis, et G.-C. Anawati, 1976 : Mystique musulmane, Paris, Vrin.

Geofrroy, Eric, 1995a : Le soufisme en Égypte et en Syrie sous les derniers Mamelouks et les premiers Ottomans: orientations spirituelles et enjeux culturels, Damas, Institut Français.

GeofrRoy, Eric, 1995b : « Le traité de soufisme d'un disciple d'Ibn Taymiyya : Aḥmad 'Imād al-dīn al-Wāsițī (m. 711/1311)», Studia Islamica, 82, p. 83-101.

Geoffroy, Éric, 1996 : «L'apparition des voies : les khirqa primitives (xII siècle - xIII ${ }^{e}$ siècle) », dans A. Popovic et G. Veinstein (dir.), Les Voies d'Allah, Paris, Seuil, p. 27-43.

Geofrroy, Eric, 2010 : «Le haschich dans les sociétés musulmanes du Proche-Orient médiéval, et en particulier chez les soufis : usages et contre-usages », dans N. ABI-RACHED (dir.), Normes et marginalités à l'épreuve, Strasbourg, Presses universitaires de Strasbourg, p. 69-74.

GLoтоN, Maurice, 2007 : Les 99 Noms d'Allâh, Beyrouth, Albouraq.

GRAHAM, William A, 1977 : Divine word and prophetic word in early Islam : a reconsideration of the sources, with special reference to the Divine Saying or Hadith Qudsî, The Hague, Walter de Gruyter \& Co.

GriL, Denis, 1996a : «Doctrine et croyances », dans A. Popovic et G. Veinstein (dir.), Les Voies d'Allah, Paris, Seuil, p. 121-138.

GriL, Denis, 1996b : « La Voie », dans A. Popovic et G. Veinstein (dir.), Les Voies d'Allah, Paris, Seuil, p. 87-103.

GriL, Denis, 1996c : « Les débuts du soufisme », dans A. Popovic et G. Veinstein (dir.), Les Voies d'Allah, Paris, Seuil, p. 27-43. 
GRIL, Denis, 2006 : « Le soufisme en Égypte au début de l'époque mamelouke d'après le Wahīd fì sulūk ahl al-tawhīi de 'Abd al-Ġaffār Ibn Nūḥ al-Qūsī (m. 708/1308) ", dans R. McGregor et A. SABRA (dir.), Le développement du soufisme en Égypte à l'époque mamelouke, Le Caire, IFAO, p. 51-73.

Homerin, Th. Emil, 1985 : «Ibn Taimīya's al-șūfīyah wa-al-fuqarā' », Arabica, 32, p. 219-244.

IBN AL-ĞAWZī, 'Abd al-Raḥmān ibn 'Alī Abū al-Farağ, Zād al-masīr fĩ 'ilm al-tafsìr, Beyrouth, al-Maktaba alislāmiyya, 1984, 9 vol.

IBN AL-NAĞĞ̄̄R, Dayl tārīh Baḡdād, Beyrouth, Dār al-kutub al-ilmiyyah, 1985, 3 vol.

IBN 'AṬıYY : al-Muharrar al-wağīz fì tafsìr al-kitāb al-'azīz, Beyrouth, Dār al-kutub al-'ilmiyya, 2001, 6 vol.

Iвn TAyмiYүA, Mağmū' al-fatāw, éd. 'Abd al-Raḥmān b. Muhammad b. Qāsim, Beyrouth, Mu'assasat al-risāla, 1978,37 vol.

Iвn TAyмrYyA, Aḥmad ibn 'Abd al-Ḥalīm Taqī al-Dīn : al-Istiqāma, Médine, Ǧāmi` al-imām Muhạmmad b. Sa'ūd, 1983, 2 vol.

IBn TaymiYya, La profession de foi d'Ibn Taymiyya : texte, traduction et commentaire de la Wāsitityya, Trad. H. Laoust, Paris, Geuthner, 1986.

KALĀBĀD̄I (AL-), Muhammad ibn Ishāa Abū Bakr, Traité de soufisme: Les Maîtres et les Étapes, trad. R. Deladrière, Paris, Actes Sud, 2005.

Karamustafa, Ahmet, 2007 : Sufism. The formative period, Edinburgh, Edinburgh University Press.

Laoust, Henri, 1939: Essai sur les doctrines sociales et politiques de Taḳi-d-Din Ahmad b. Taimìya, canoniste hanbalite né à Harran en 661/1262, mort à Damas en 728/1328, Le Caire, IFAO.

Laoust, Henri, 1960 : « Le hanbalisme sous les Mamlouks bahrides », Revue des Études Islamiques, 28, p. 1-71.

LAoust, Henri, 1962 : «Le réformisme d'Ibn Taymiya », Islamic Studies 1/3, p. $27-47$.

MAKDISI, George, 1963 : Ibn 'Aqïl et la résurgence de l'islam traditionaliste au xI siècle (ve siècle de l'hégire), Damas, Institut français.

MAKDISI, George, 1973 : « Ibn Taimīya : a șūfī of the Qādiriya order », American Journal of Arabic Studies 1, p. 118-129.

MAKDISI, George, 1974 : «The Hanbali School and Sufism ». Hamadard Islamica 11, p. 61-72.

MAKDISI, George, 1983 : L'islam hanbalisant, Paris, Geuthner.

MAKDISI, George, 1984 : «Soufisme et Hanbalisme dans l'œuvre de Massignon », dans Centenaire de Louis Massignon, Le Caire, Université du Caire, p. 79-85.

MAKкī (AL-), Abū Țālib, Qūt al-qulūb fì mu'āmalat al-maḥbūb wa wașf țarīq al-murīd ilā maqām al-tawhìd, Beyrouth, Dār Șādir, 2007, 2 vol.

MAssignon, Louis, 1999 (rééd.) : Essai sur les origines du lexique technique de la mystique musulmane, Paris, Cerf. MĀWARDĩ (AL-), 'Alī ibn Muhammad, al-Nukat wa al-'uyūn, Beyrouth, Dār al-kutub al-ilmiyya, s. d., 6 vol.

McGregor, Richard, 2009 : «The Problem of Sufism », Mamlūk Studies Review 13/2, p. 69-83.

Melchert, Christopher, 1996: «The Transition from Asceticism to Mysticism at the Middle of the Ninth Century C.E. », Studia Islamica 83, p. 51-70.

MelcherT, Christopher, 2006 : Ahmad ibn Hanba, Oxford, Oneworld.

Mıchel, Thomas, 1981 : « Ibn Taymiyya's sharh on the Futūh al-ghayb of 'Abd al-Qādir al-Jīlānī », Hamdard Islamicus 4/2, p. 3-12.

Мıснот, Jean, 1991 : Musique et danse selon Ibn Taymiyya, Paris, Vrin.

Мıснот, Yahya, 2001a : Le haschich et l'extase, Beyrouth, Albouraq.

Міснот, Yahya, 2001b : « Un célibataire endurci et sa maman : Ibn Taymiyya (m. 728/1328) et les femmes », Acta Orientalia Belgica 15, p. 165-190.

Мıснот, Yahya, 2003 : «S Suivre Muhammad par amour de Dieu », dans Iвn TAYмiYYA, Pages spirituelles I-XXI, trad. Y. Міснот, Oxford, le Chebec [est en ligne sur le site www.muslimphilosophy.com]. 
Мıснот, Yahya, 2004 : Un dieu hésitant ?, Beyrouth, Albouraq.

Міснот, Yahya, 2007 : Les saints du Mont Liban, Beyrouth, Albouraq.

MouRAD, Ali Suleiman, 2006 : Early Islam between myth and history : Al-Hasan al-Bașrī, d. 110H/728CE, and the formation of his legacy in classical Islamic scholarship, Leiden, Brill.

Musum, Abū al-Ḥusayn ibn al-Ḥaǧğāğ al-Qušayrī al-Naysābūrī, al-Ṣahịḥ, Beyrouth, Dār ihyāà al-kutub al--'arabiyya, 1991, 5 vol.

NwyiA, Paul, 1991 (2e éd.) : Exégèse coranique et langage mystique : nouvel essai sur le lexique technique des mystiques musulmans,Beyrouth, Dar el-Machreq.

OlESEN, Niels Henrik, 1991 : Culte des saints et pèlerinages chez Ibn Taymiyya, Paris, Geuthner.

Peskes, Esther, 1999: "The Wahhābiyya and Sufism in the Eighteenth Century », dans F. De Jong and B. RADTKE (dir.), Islamic Mysticism Contested: Thirteen Centuries of Controversies and Polemics, Leiden, Brill, p. 145-161.

PouzET, Louis, 1983 : « Prises de position autour du "samâ" en Orient musulman au VII ${ }^{e} /$ XIII $^{e}$ siècle », Studia Islamica 57, p. 119-134.

Pouzet, Louis, 1991 (2e éd.) : Damas au VII $/ \mathrm{XIII}^{e}$ siècle : vie et structures religieuses d'une métropole islamique, Beyrouth, Dar el-Machreq .

QUŠAYRī (AL-), 'Abd al-Karīm ibn Hawāzin Abū al-Qāsim al-Naysabūrī, al-Risāla al-qušayriyya, Le Caire, Dār al-Ma'ārif, 1995, 2 vol.

Rāzī (AL-), Muḥammad ibn 'Umar Faȟr al-Dīn, Mafātīh al-ġayb (al-Tafsīr al-kabīr), Beyrouth, Dār al-fikr, 1981.

RitTer, Helmut, 1970 : « Ḥasan al-Bașrī », Encyclopédie de l'Islam, 2éd., Leiden, Brill, vol. 3, p. 247-248.

Haqāì al-tafsìr, Beyrouth, Dār al-kutub al-ilmiyya, 2001, 2 vol.

Sulamī (AL-), 'Abd al-Raḥmān, Ziyādāt haqā̄iq al-tafsīr, Beyrouth, Dār al-mašriq, 1995, 2 vol.

Ṭ̂ABRī (AL-), Muḥammad ibn Ǧarīr ibn Yazīd, Ğāmi' al-bayān 'an ta'wīl āyi al-Qur'ān, Le Caire, Hiğr, 2001, $26 \mathrm{vol}$.

T⿱A Á LABī (AL-), Abū Ishāq, al-Kašf wa-l-bayān fi-tafsīr al-Qur'ān, Beyrouth, Dār ihyā̄' al-turāt al-'arabiyya, 2001, 10 vol.

Thibon, Jean-Jacques, 2009 : L'œuvre d'Abū 'Abd al-Rahmān al-Sulamī (325/937-412/1021) et la formation du soufisme, Damas, Presses de l'Ifpo.

URVoY, Dominique, 2006 : Histoire de la pensée arabe et islamique, Paris, Seuil.

WATT, W. Montgomery, 1960 : «Ahl al-ṣuffa », Encyclopédie de l'Islam, 2 éd., Leiden, Brill, vol. 1, p. 266. 
